\title{
Social organisational LCA for the academic activity of the University of the Basque Country UPV/EHU
}

\author{
Artitzar Erauskin-Tolosa ${ }^{1,2}\left({ }^{3} \cdot\right.$ Gorka Bueno $^{3,4,5} \cdot$ Iker Etxano $^{4,5,6} \cdot$ Unai Tamayo ${ }^{7} \cdot$ María García $^{8} \cdot$ Maite de Blas $^{9}$. \\ Estibaliz Pérez-Iribarren ${ }^{3} \cdot$ Iñaki Zuazo $^{10} \cdot$ Eduardo Torre-Pascual $^{9} \cdot$ Ortzi Akizu-Gardoki $^{5,10}$
}

Received: 1 March 2021 / Accepted: 8 June 2021 / Published online: 15 July 2021

(c) The Author(s) 2021

\begin{abstract}
Purpose This article aims to estimate the social footprint of a higher education institution (HEI) and its potential contribution to Sustainable Development Goals (SDGs) under life cycle assessment (LCA) perspective. The social organisational life cycle assessment (SO-LCA) of the academic activity of the University of the Basque Country (UPV/EHU), in northern Spain, has been performed, in order to estimate its social impacts.

Method The assessment has been run using openLCA software and supported on the PSILCA-based Soca add-on for the Ecoinvent v3.3 database, covering 53 social indicators for almost 15,000 industrial sectors and goods in 189 countries.

Results and discussion The analysis undertaken reflects social impacts and associated risk levels for four stakeholders: Workers, Local Community, Society, and Value Chain Actors. Labour activity in the UPV/EHU is the sub-process with the greatest social impact, followed by processes related to transport, energy, materials, and waste management. Among the socio-economic context which supports the academic activity of the UPV/EHU (indirect impacts), the existence of traces of child labour and illiteracy outside the Basque Country stands out. Further analysis would be required in order to more accurately determine the geographical location of such impacts, and also to better tackle the concept of social debt. Conclusion SO-LCA may have great potential for HEIs, helping them to identify hotspots, reduce their social footprint, and raise awareness among the academic community, which undoubtedly contributes to the knowledge, progress, human values, and sustainability these HEIs stand for.
\end{abstract}

Keywords Social organisational LCA $\cdot$ SO-LCA $\cdot$ Higher education institution $\cdot$ Soca $\cdot$ Social footprint $\cdot$ Social debt $\cdot$ SDG

Communicated by: Marzia Traverso

Artitzar Erauskin-Tolosa

artitzar.erauskin@ehu.eus

1 Department of Applied Economics, University of the Basque Country UPV-EHU, Oñati Plaza 1, 20018 Donostia-San Sebastian, Spain

2 GEZKI-Institute of Social Economy and Cooperative Law, University of the Basque Country UPV/EHU, Elhuyar Plaza, 20018 Donostia, Spain

3 Department of Electronics Engineering, University of the Basque Country UPV-EHU, Plaza Ingeniero Torres Quevedo, 1, 48013 Bilbao, Spain

4 Hegoa - Institute for International Cooperation and Development Studies, University of the Basque Country UPV-EHU, Lehendakari Agirre Etorbidea, 83, 48015 Bilbo, Spain

5 EKOPOL Research Group, University of the Basque Country UPV/EHU, Sarriena z/g, 48940 Leioa, Spain
6 Department of Applied Economics, University of the Basque Country UPV-EHU, Sarriena auzoa z/g, 48940 Leioa, Spain

7 Department of Finance Economics II, University of the Basque Country UPV-EHU, Lehendakari Agirre Etorbidea, 83, 48015 Bilbo, Spain

8 Department of Applied Economics, University of the Basque Country UPV-EHU, Comandante Izarduy, 23, 01006 Vitoria-Gasteiz, Spain

9 Department of Chemical and Environmental Engineering, University of the Basque Country UPV-EHU, Ingeniero Torres Quevedo Plaza, 1, 48013 Bilbo, Spain

10 Department of Graphic Design and Engineering Projects, University of the Basque Country UPV-EHU, Ingeniero Torres Quevedo Plaza, 1, 48013 Bilbo, Spain 


\begin{tabular}{|c|c|}
\hline \multicolumn{2}{|c|}{ Abbreviations } \\
\hline $\mathrm{ACBC}$ & $\begin{array}{l}\text { Autonomous Community of the Basque } \\
\text { Country }\end{array}$ \\
\hline HEI & Higher education institution \\
\hline LCA & Life cycle assessment \\
\hline LCIA & Life cycle impact assessment \\
\hline O-LCA & Organisational life cycle assessment \\
\hline PSILCA & $\begin{array}{l}\text { Product Social Impact Life Cycle Assess- } \\
\text { ment Database }\end{array}$ \\
\hline Soca & $\begin{array}{l}\text { Add-on for the Ecoinvent v3.3 database pro- } \\
\text { viding information for Social LCA, based on } \\
\text { PSILCA and developed by GreenDelta }\end{array}$ \\
\hline S-LCA & Social life cycle assessment \\
\hline SO-LCA & Social organisational life cycle assessment \\
\hline UPV/EHU & $\begin{array}{l}\text { Universidad del País Vasco/Euskal Herriko } \\
\text { Unibertsitatea }\end{array}$ \\
\hline
\end{tabular}

\section{Introduction}

The social effects associated with higher education are seen as positive, as it contributes to boosting knowledge, culture, human values, and progress. Higher education is also relevant in the field of sustainability, contributing to it both through research and training, and by means of institutional commitment (Lozano et al. 2015). However, like any other economic activity, an academic one may have negative impacts not only on its immediate environment but also along its value chain, according to a life cycle perspective. In fact, several studies have assessed the environmental impact of higher education institutions (HEIs) (see, e.g. Lopes Silva et al. 2015; Sinha et al. 2010), but those considering social impacts are not as common (Petti et al. 2018).

Life cycle assessment (LCA) is a methodology used worldwide for estimating the impacts of a given economic activity, a company or a product/service throughout its life cycle (Hauschild et al. 2018). Accordingly, social LCA (S-LCA) is an expansion of the LCA framework incorporating the assessment of social impacts (Moltesen et al. 2018). Thus, under a life cycle perspective, S-LCA contributes to (1) identifying the social changes, (2) characterising them, and (3) evaluating them in relation to how they contribute to human well-being. Although S-LCA is still in its infancy, it is presented as a tool capable of reflecting changes in the well-being of stakeholders, which is relevant in terms of both social justice and sustainability. Compared to environmental LCA, the causality between processes and impacts is weaker in S-LCA because social impacts depend on multiple factors. This makes S-LCA less meaningful as a decision support tool. Nevertheless, S-LCA has already been applied to products such as laptop computers (Ciroth and Franze 2011), and to sectors such as rare earth mining (Werker et al. 2019), wood-based production (Jarosch et al.
2020), mobility services (Gompf et al. 2020), and wine production (D'Eusanio et al. 2020). Many applications have benefited from the Guidelines for Social Life Cycle Assessment of Products (Benoît and Mazijn 2009), a document that has become elementary in the field. Its recent update (Benoît et al. 2020) focuses not only on products but also on organisations. Even so, this methodology still has significant room for development both in terms of foundational issues (e.g. the concept of well-being) and more technical aspects (e.g., indicator development, valuation methods) (Moltesen et al. 2018).

In parallel, organisational LCA (O-LCA) methodology has also undergone interesting developments in recent years (Martínez-Blanco and Finkbeiner 2018). O-LCA is devoted to improving the environmental performance of an organisation by estimating the environmental impacts derived from its activity (Martínez-Blanco et al. 2015a). Two important milestones in its development have been the publication of the European Commission's Organisation Environmental Footprint (OEF) Guide (Pelletier et al. 2012, 2014), and that of Guidance on organizational LCA launched by UNEP/ SETAC (UNEP/SETAC 2015). Thus, O-LCA has gained presence through applications in various sectors such as automotive, cosmetics, food, and construction materials (Forin et al. 2019), including the academic activity of HEIs (Lo-Iacono-Ferreira et al. 2017).

The methodological approach of combining S-LCA and O-LCA is known as social organisational life cycle assessment (SO-LCA) (Martínez-Blanco et al. 2015b; Benoît et al. 2020). SO-LCA is an emerging methodology that will undoubtedly contribute to broadening the practical examination of the social aspects of organisations from a life cycle perspective. In this study, we have applied the SO-LCA framework to the University of the Basque Country (UPV/ EHU) to estimate various social impacts. This assessment will make it possible to estimate the social footprint of the UPV/EHU and its potential contribution to Sustainable Development Goals (SDGs). To date, there are few studies that analyse the life cycle impact of products and services on SDGs. However, according to Herrera Almanza and Corona (2020), evaluation and monitoring systems can be an effective tool for understanding and improving the contribution made by academic activities to the achievement of SDGs.

Our study builds on the results obtained from the modelling of the academic activity performed in buildings at the UPV/EHU in 2016, when they were used by almost $97 \%$ of the academic community (both students and staff). The modelling considers various inflows (supply of energy and materials) and outflows (several hazardous and nonhazardous waste fractions) as well as transportation needs. The details of this modelling are specified by Bueno et al. (2021) when calculating the organisational LCA of the UPV/EHU, which also provides detailed 
information on the environmental impacts derived from the academic activity, offering the indispensable complementary view to that offered by the social impacts analysed in this paper. To our knowledge, there are no studies reporting the SO-LCA of an HEI, so this paper aims to further develop the application of the S-LCA within an organisational context by means of such a case study.

The reporting organisation in this work is the UPV/ EHU, the main HEI in the Autonomous Community of the Basque Country (ACBC, northern coast of Spain), comprising nearly 47,000 users made up of students, administration and service staff, and teaching and research staff. It is the only public university in the ACBC and has faculties on its three campuses, one in each province (Araba, Bizkaia, Gipuzkoa). The UPV/EHU is institutionally aligned with the 2030 Agenda for Sustainable Development and the SDGs by means of its own agenda called EHUagenda 2030 (UPV/EHU, 2019a), which will be monitored using a panel of indicators (UPV/EH 2019b). In addition, the UPV/EHU has launched the IKD $\mathrm{i}^{3}$ teaching-learning model, which consists in multiplying learning through research and sustainability, so that new processes and products are made possible. The UPV/EHU has made a commitment to the future, its roadmap having a time perspective up to 2030, although in 2025 an evaluation will be made that will establish the lines of work to be followed (Sáez de Cámara et al. 2021).

Given this context, the objectives of the paper are twofold: (1) to identify the social impacts associated with the academic activity of the UPV/EHU and (2) to estimate their scope in terms of the stakeholders affected and territorial location. Thus, the assessment will provide reliable information, with two main goals in mind, on the one hand, to raise awareness among the UPV/EHU academic community of its own impacts, and, on the other, to establish a number of measures to mitigate adverse impacts within SDG framework. Ultimately, all of this would undoubtedly contribute to making the UPV/EHU socially more equitable and sustainable.

The remainder of the paper is structured as follows: Sect. 2 presents the materials and methods used, divided into SO-LCA (Sect. 2.1), goal and scope definition (Sect. 2.2), social life cycle inventory analysis (Sect. 2.3), and social life cycle impact assessment (Sect. 2.4). Section 3 presents the results of the assessment in terms of stakeholders involved, contributing factors, and location of impacts, which are discussed in Sect. 4. The article concludes with a series of relevant conclusions that may be of interest to the HEIs in order to reduce the social impact derived from their activity (Sect. 5). Additional details on primary and secondary data, methodology, and results will be presented in another dataset article (Bueno G, de Blas M, Pérez-Iribarren E et al. Dataset on the environmental and social footprint of the University of the Basque Country UPV/EHU, Unpublished work).

\section{Materials and methods}

\subsection{Social organisational LCA}

This section describes the methodology for the assessment of social impacts, which makes use of the PSILCA-based Soca add-on for the Ecoinvent v3.3 database (Ciroth and Eisfeldt 2016; Eisfeldt 2017), running on the openLCA software (Ciroth 2007). Fifty-three social impact indicators provided by the Social Impact Weighting Methodand included in Soca-have been considered Tables 3, 4, 5 and 6 with a more disaggregated analysis of ten selected social impact indicators (marked with an asterisk in Tables 3, 4, 5 and 6; costs are also analysed). A disaggregated analysis of the 53 social impact indicators is beyond the scope of this study, as its main goal was to test the methodology. Our selection for disaggregated analysis has avoided the processing of very similar indicators or those with qualitative or binary results. The ten selected social impact indicators cover seven impact categories out of seventeen, across the four stakeholders considered in Soca.

The calculation of social impacts is performed as follows: the Soca add-on combines social information from the PSILCA database to the Ecoinvent database and allows the combination of S-LCA and E-LCA (Social and Environmental Life Cycle Assessment) and LCC (Life Cycle Costing). Figure 1 shows, as an example of the methodology, a diagram for the processing of social impacts related to the simplified life cycle of a computer, where only three productive sectors involved are taken into account: computer production (Sector 1), energy supply (Sector 2), and materials supply (Sector 3).

The calculation of social impacts with openLCA and the Ecoinvent database is based on a modelling process that assigns an economic sector of a country or world region to each of the sub-processes involved in the life cycle of the products or services under study (i.e. Sectors 1, 2, and 3 for the production of one computer). In particular, the Soca module adds social aspects from the PSILCA databasewhich covers 53 social indicators for almost 15,000 industrial sectors and commodities in 189 countries (Ciroth and Eisfeldt 2016) — to the Ecoinvent database for openLCA.

The activity variable considered for the calculation of social impacts is the "working hours" in each of the processes modelled, in this case for the production of a computer in Sectors 1, 2, and 3. These working hours are calculated by openLCA based on the quantities of the modelled product and service flows, their prices (available in Ecoinvent v3.3), and the estimates of the labour costs in the economic sectors (obtained from PSILCA through Soca).

The results of the modelling of social impacts are provided by Soca in the form of "risk hours," according to 


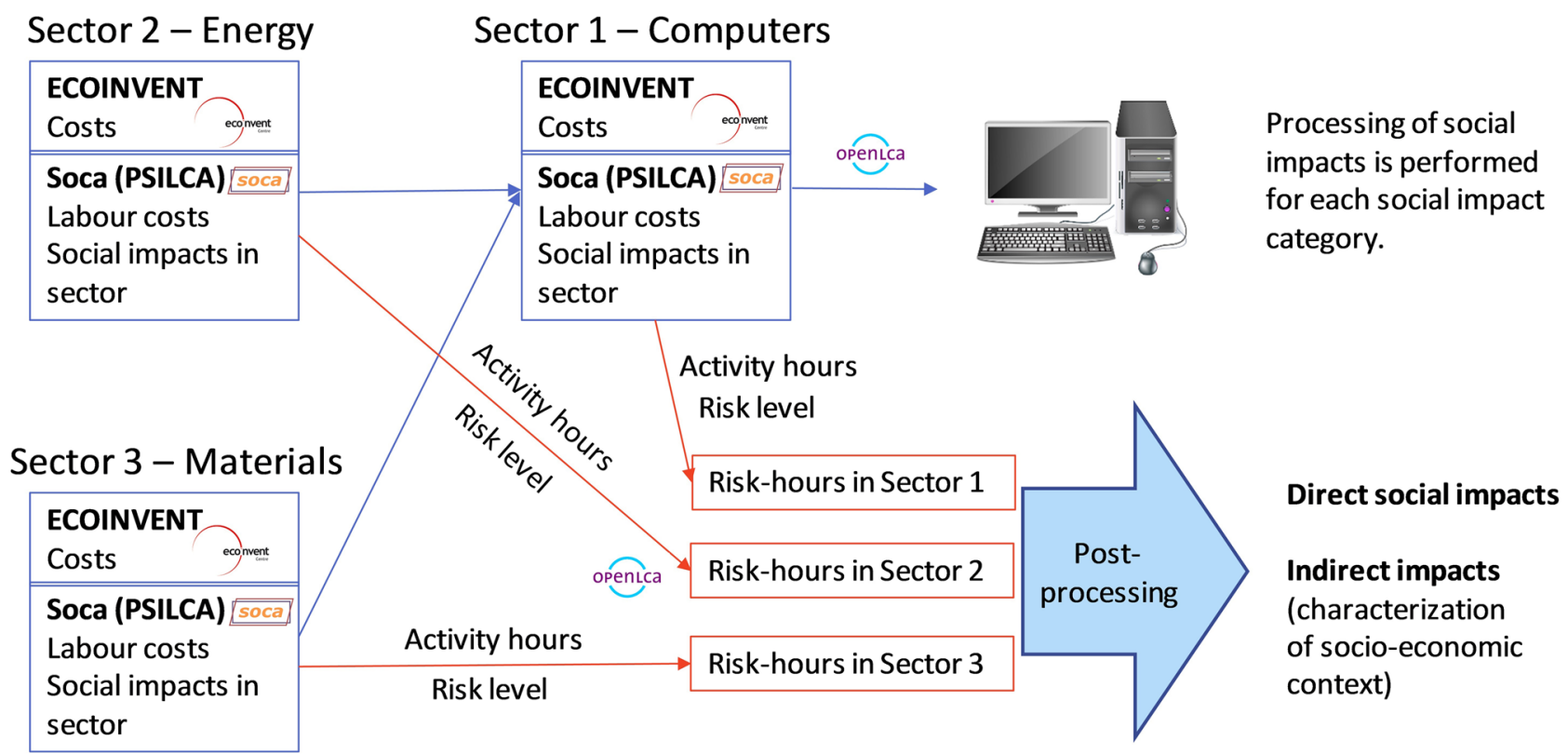

Fig. 1 Diagram for the processing of social impacts related to the simplified life cycle of a computer, with only three productive sectors involved (computer production, energy supply, materials supply).

different levels of risk (from non-existent to very high; see Tables 3, 4, 5 and 6). The level of risk is defined by the Soca module for each process and location (country or region), based on the data incorporated from PSILCA.

Social impacts are measured in risk hours, which are the total working hours linked to a product or service in economic sectors, and they are associated with a specific level of risk (very low, low, medium, high, very high, no risk), characteristic of the economic sector in which the activity hours are accounted for. Specifically, total social impacts are provided by Soca in terms of equivalent medium-risk hours, for which it considers in its calculations various specific equivalences across the different risk levels-normally applying a factor of ten $(\times 10)$ from one risk level to the next. For example, ten medium-risk hours are considered equivalent to one high-risk hour. This equivalence, however, seems arbitrary: for the case of the impact category of "fatal accidents at work," PSILCA assigns a medium risk level to sectors with a fatal accident rate of between 15 and 25 fatal accidents per year per 100,000 workers, and a high risk level to sectors with a fatal accident rate of between 25 and 40 fatal accidents per year per 100,000 workers (Ciroth and Eisfeldt 2016). In this case, an equivalence factor of 1.6 $(32.5 / 20)$ would seem more appropriate.

Our work has followed an alternative strategy to calculate all the equivalence factors among the different risk levels for each of the social impact categories. This strategy requires a further processing of data provided by Soca, and appropriate interpretation. Post-processing is performed as follows: our
Post-processing of risk-hours provided by Soca and openLCA is performed for each of the 53 social impact indicators considered by the Social Impact Weighting Method

analysis recalculates the impact in one category for each economic sector and region involved in the life cycle under study, assigning to the impact factor (e.g. fatal accidents per activity-hour with a specific risk level) the central value from the value range considered by PSILCA for each level of risk. In the case of fatal accidents, 20 fatal accidents are assumed for a medium risk level (value range [15-25]), and 32.5 fatal accidents per year per 100,000 workers for a high risk level (value range [25-40]). The impact factors considered for each risk level in each impact category are shown in Tables 3, 4, 5 and 6. This calculation allows us to calculate the final aggregate social impacts in such a way that, although approximate, is also more accurate, without arbitrary risk level equivalences. This post-processing of risk hours provided by Soca and openLCA must be performed for each of the 53 social impact indicators defined by the Social Impact Weighting Method. Additionally, in Tables 3, 4, 5 and 6, each social impact indicator is linked with a particular SDG, following the classification criteria proposed by Herrera Almanza and Corona (2020).

At this point, it must be noted that these social impact indicators provide information of two different kinds. While some indicators provide information on the direct impact related to the socio-economic activity involved in the life cycle of the product or service under study-e.g. the impact categories related to accidents at work, or the economic costs-other social indicators, which we label as indirect social impact indicators, provide information on the socioeconomic context of the life cycle under study—-such as 
illiteracy, social spending on health, child labour, or a gender wage gap. The divergence of this characterisation from that corresponding to the local context in which the final product or service is consumed can be interpreted as an indicator of indirect social impacts - the social footprint - of the life cycle of that product or activity.

\subsection{Goal and scope definition}

The assessment of the social footprint of the UPV/EHU has been carried out in the context of the EHU-Aztarna project, which involves the participation of a multidisciplinary team made up of teaching and research staff, administration and service staff, as well as students of the UPV/EHU, and aims to calculate the environmental and social impacts of the UPV/EHU (Bueno et al. 2021), in order to (1) monitor its performance for a reference year and (2) identify the environmental and social hotspots related to its academic activity. The modelling of the environmental and social impacts of the UPV/EHU has been carried out taking 2016 as a base year, following the guides provided by the European Commission (Pelletier et al. 2012) and the UNEP/ SETAC Life Cycle Initiative (UNEP/SETAC 2015). The work covered in this article aims to calculate the organisational social footprint of the academic activity of the UPV/ EHU using the LCA methodology (SO-LCA).

The faculties and schools of the UPV/EHU-around 30 - are distributed into three campuses, one for each of the three provinces of the ACBC: the Campus of Araba (located in Vitoria-Gasteiz), Campus of Bizkaia (Leioa, Bilbao, and Portugalete), and Campus of Gipuzkoa (Donostia-San Sebastián and Eibar) (UPV/EHU 2020a). Adding staff and students, the UPV/EHU had 46,813 users in 2016, and a budget of 402 million euros. In the 2016/17 academic year, 68 Bachelor's degrees, 111 Official postgraduate Master's courses, $65 \mathrm{PhD}$ programmes, and 34 own qualifications were offered (UPV/EHU 2020b, c).

The scope of our modelling, considering various inflows and outflows, as well as the transportation needs of the academic community (students and staff), has covered the academic activity in buildings that were used by or involved the academic activity of 45,306 users, accounting for
$96.8 \%$ of the total users of the UPV/EHU. The reporting flow in this work is the academic activity performed in year 2016 in these buildings, which are considered the reporting unit (Martínez-Blanco et al. 2015c; Benoît et al. 2020).

Table 1 shows the users associated with faculties, centres, and buildings under management of the UPV/EHU, in the 2016/17 academic year. No faculty was excluded from the Araba Campus. For the Bizkaia and Gipuzkoa Campuses, Medicine Teaching Units (accounting for $<2.5 \%$ of total users) were excluded, as they are based in University Hospitals whose direct management is not the responsibility of the UPV/EHU. The Faculty of Engineering headquarters in Portugalete (School for Navigation and Naval Machines) was also excluded, since it accounts for only $0.6 \%$ of the total users. Some other entities managed by the UPV/EHU were also excluded from the study, as they are isolated from other buildings and have less than 25 users. These are university residences on all three campuses, some specific research centres, and some isolated common infrastructures where the inventory phase presented serious problems from the point of view of data collection and allocation.

\subsection{Social life cycle inventory analysis}

The modelling carried out for the academic activity of the UPV/EHU is based on the inventory of both consumption (electricity, fuels, main materials, and products) and waste fluxes (urban waste, hazardous waste, electrical and electronic equipment waste, wastewater). Table 2 shows the main fluxes considered, and their quantification at the three campuses and some specific faculties located outside the campuses.

As noted, the modelling for the academic activity of the UPV/EHU, carried out with openLCA and the Ecoinvent database, assigns an economic sector of a country or world region to each of the activities present in the life cycle that supports the academic activity of the UPV/EHU. For the allocation of the work activity of staff within the UPV/ EHU-the activity variable considered for the calculation of social impacts - an annual working day of $1500 \mathrm{~h}$ is assumed. The average labour cost at the UPV/EHU was derived from the annual budgets of the UPV/EHU for 2016

Table 1 Number of students, teaching and research staff, and administration and service staff at the UPV/EHU, 2016/17 academic year, and buildings and users included in the analysis

\begin{tabular}{lllllll}
\hline Campus & Students & $\begin{array}{l}\text { Teaching and } \\
\text { research staff }\end{array}$ & $\begin{array}{l}\text { Admin and } \\
\text { services staff }\end{array}$ & $\begin{array}{l}\text { Faculties and buildings con- } \\
\text { sidered in the analysis }\end{array}$ & $\begin{array}{l}\text { Users (students + staff) } \\
\text { included in the analysis }\end{array}$ & $\begin{array}{l}\text { Percentage of } \\
\text { users included } \\
(\%)\end{array}$ \\
\hline Araba & 7163 & 979 & 254 & 11 & 8396 & $19.9 \%$ \\
Bizkaia & 22,078 & 3241 & 1219 & $25(4$ in Bilbao $)$ & 25,411 & $54.3 \%$ \\
Gipuzkoa & 10,119 & 1376 & 384 & $16(1$ in Eibar $)$ & 11,499 & $24.6 \%$ \\
Total & 39,360 & 5596 & 1857 & 52 & 45,306 & $96.8 \%$ \\
\hline
\end{tabular}


Table 2 Inventory of flows of energy consumption, material consumption, waste generation, and transportation needs that support the academic activity of the UPV/EHU in 2016 for Leioa campus (Leioa); Faculty of Engineering (EIB-Bilbao), Sarriko and Elkano
(Faculty of Economics and Business) in Bilbao; Donostia campus (Donostia-San Sebastián); Faculty of Engineering headquarters in Eibar (Eibar); and Araba campus (Vitoria-Gasteiz) (Bueno et al. 2021)

\begin{tabular}{|c|c|c|c|c|c|c|c|c|}
\hline Concept & Unit & Leioa & EIB-Bilbao & Sarriko & Elkano & $\begin{array}{l}\text { Donostia-San } \\
\text { Sebastián }\end{array}$ & Eibar & Vitoria-Gasteiz \\
\hline Users & Person & 15,024 & 5865 & 3441 & 1086 & 11,879 & 344 & 8396 \\
\hline \multicolumn{9}{|l|}{ Energy resources } \\
\hline Electricity & MWh & 15,989 & 4204 & 1019 & 168 & 7400 & 100 & 5074 \\
\hline Natural gas & MWh & 14,192 & 1985 & 2194 & 178 & 8834 & 0 & 7727 \\
\hline Gas-oil & $\mathrm{L}$ & 0 & 113,694 & 0 & 0 & 90 & 39,000 & 0 \\
\hline \multicolumn{9}{|l|}{ Material resources } \\
\hline Water supply & $\mathrm{m}^{3}$ & 116,963 & 23,718 & 9925 & 1085 & 27,979 & 350 & 19,045 \\
\hline Paper (recycled and non-recycled) & $\mathrm{kg}$ & 55,022 & 29,702 & 8738 & 1263 & 18,939 & 323 & 13,183 \\
\hline Computers & Units & 1161 & 643 & 235 & 59 & 977 & 46 & 545 \\
\hline Batteries & $\mathrm{kg}$ & 421.5 & 65.8 & 80 & 14 & 81 & 4 & 185 \\
\hline Fluorescent lamps & Units & 10,623 & 2400 & 260 & 38 & 500 & 200 & 200 \\
\hline Toners & Units & 1083 & 277 & 214 & 150 & 661 & 40 & 803 \\
\hline \multicolumn{9}{|l|}{ Waste treatment } \\
\hline Hazardous waste & $\mathrm{kg}$ & 23,076 & 3756 & 0 & 0 & 25,576 & 0 & 9718 \\
\hline $\begin{array}{l}\text { Non-hazardous waste } \\
\text { (several fractions) }\end{array}$ & $\mathrm{kg}$ & 379,993 & 74,624 & 68,347 & 20,592 & 73,397 & 5600 & 101,523 \\
\hline WEEE & $\mathrm{kg}$ & 10,704 & 3500 & 1907 & 900 & 2352 & 3000 & 2080 \\
\hline \multicolumn{9}{|l|}{ Transport } \\
\hline Transport needs & $\times 10^{6} \mathrm{p} \cdot \mathrm{km}$ & 141.2 & 41 & 23.9 & 7.3 & 101 & 3.1 & 84.9 \\
\hline
\end{tabular}

(UPV/EHU 2020b). The social impacts of labour activity in the UPV/EHU have been modelled by adjusting the indicators when available for the Basque Country, and otherwise assuming those of Spain (see Tables 7, 8, 9, and 10).

\subsection{Social life cycle impact assessment}

The Guidelines for the social LCA of products proposed by UNEP/SETAC in 2009 identified five relevant stakeholder groups: Workers, Local Community, Society, Value Chain Actors and Consumers (Benoît and Mazijn 2009; Benoît et al. 2013). The recently updated new Guidelines add a new stakeholder to the previous five: Children (Benoît et al. 2020). The present study provides a quantitative analysis for the stakeholders Workers, Local Community, Society and Value Chain Actors, as these are the ones for which the Soca module provides social impact results through its social LCIA method, the Social Impact Weighting Method (Eisfeldt 2017). Tables 3, 4, 5, and 6 below show the social impact indicators in each impact category, their short definition, and the unit of measurement provided by the Soca module for each impact category for the four main stakeholders considered. The 10 indicators marked with an asterisk (*) are subject to a more detailed disaggregated analysis. Additionally, in Tables 3, 4, 5, and 6, each social impact indicator is linked with one of the 17 SDGs following the classification proposed by Herrera Almanza and Corona (2020), which makes it possible to classify 53 social impact indicators into 10 SDGs.

\section{Results}

The results of the analysis for the four stakeholders and the comparison of risks levels on each impact category are shown in Tables 7, 8, 9, and 10 .

Table 7 shows the social impacts of the academic activity of UPV/EHU for the Workers stakeholder. The associated risk level for 12 out of 22 social impact indicators is very low (6), low (5), or medium (1). The risk level for four social impact indicators, living wage, gender wage gap, violations of employment laws and regulations, and trade unionism, is high, and for the sector average wage impact indicator, it is very high. In addition, four social impact indicators show no risk: goods produced by forced labour, which belongs to the forced labour impact category, and three social impact indicators of the workers' rights impact category, namely, right of association, right of collective bargaining and right to strike. Finally, social impact data for weekly hours of work per employee is not available. In addition, it should be noted that categories with two results contain both direct impacts (in 


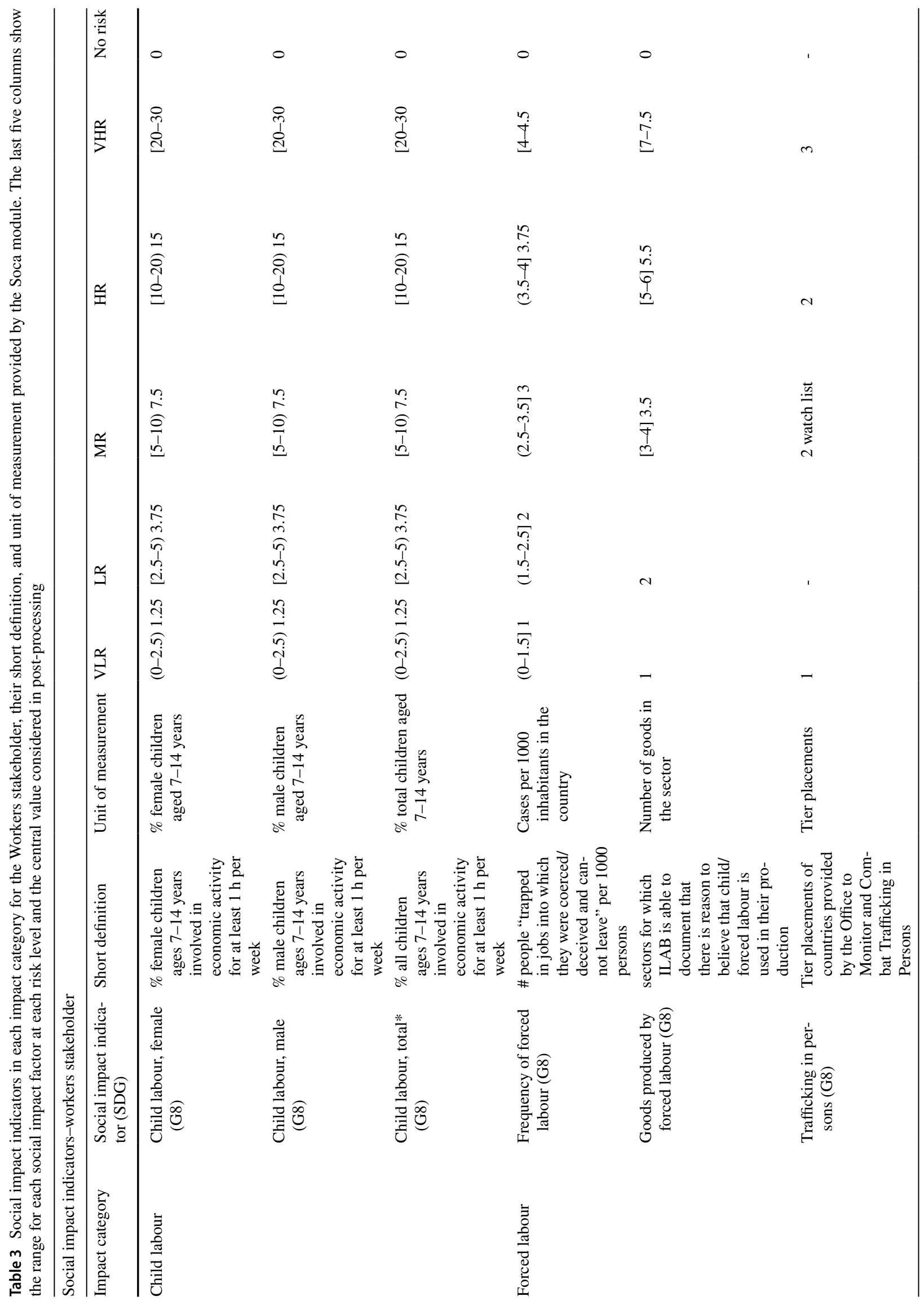




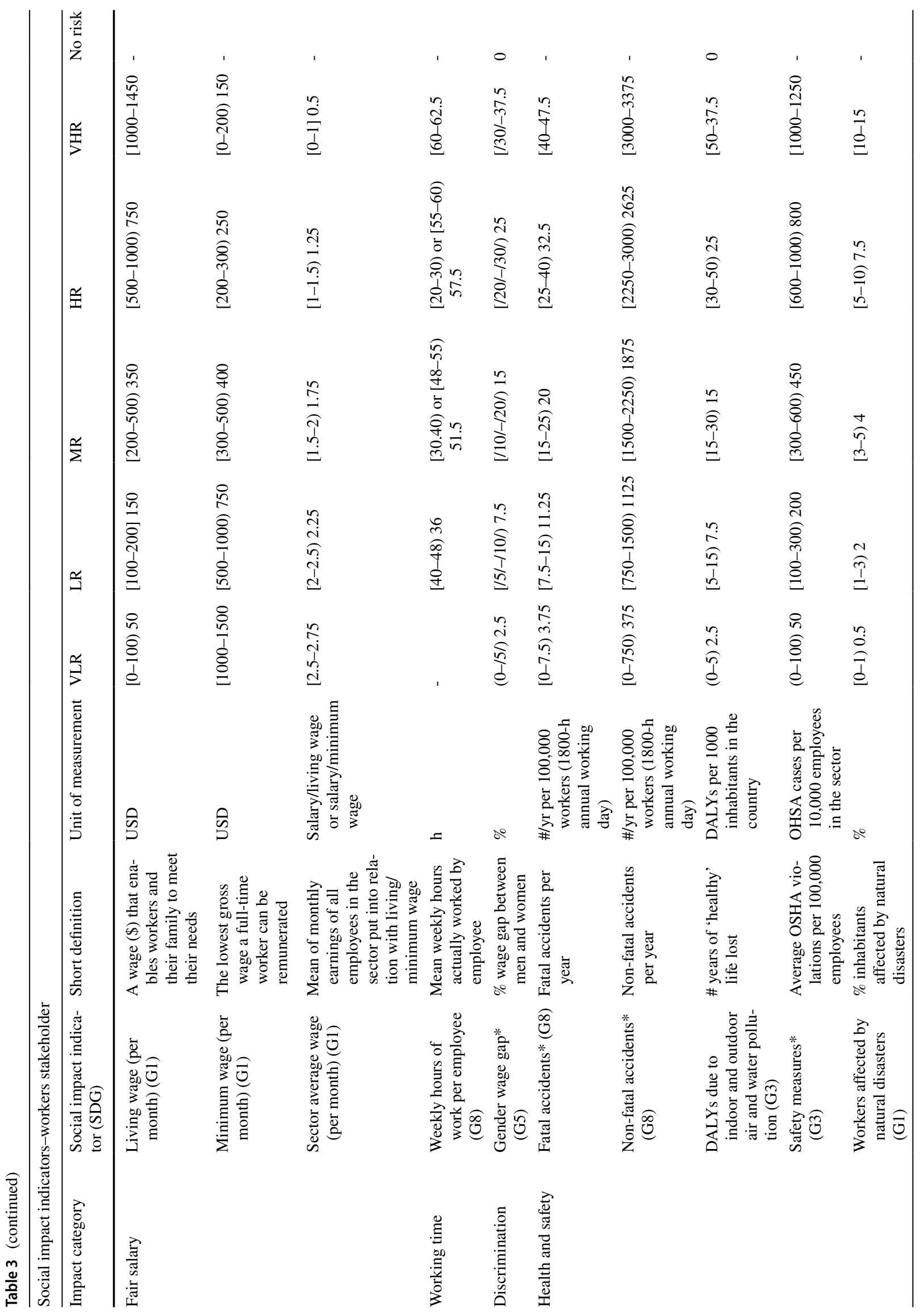




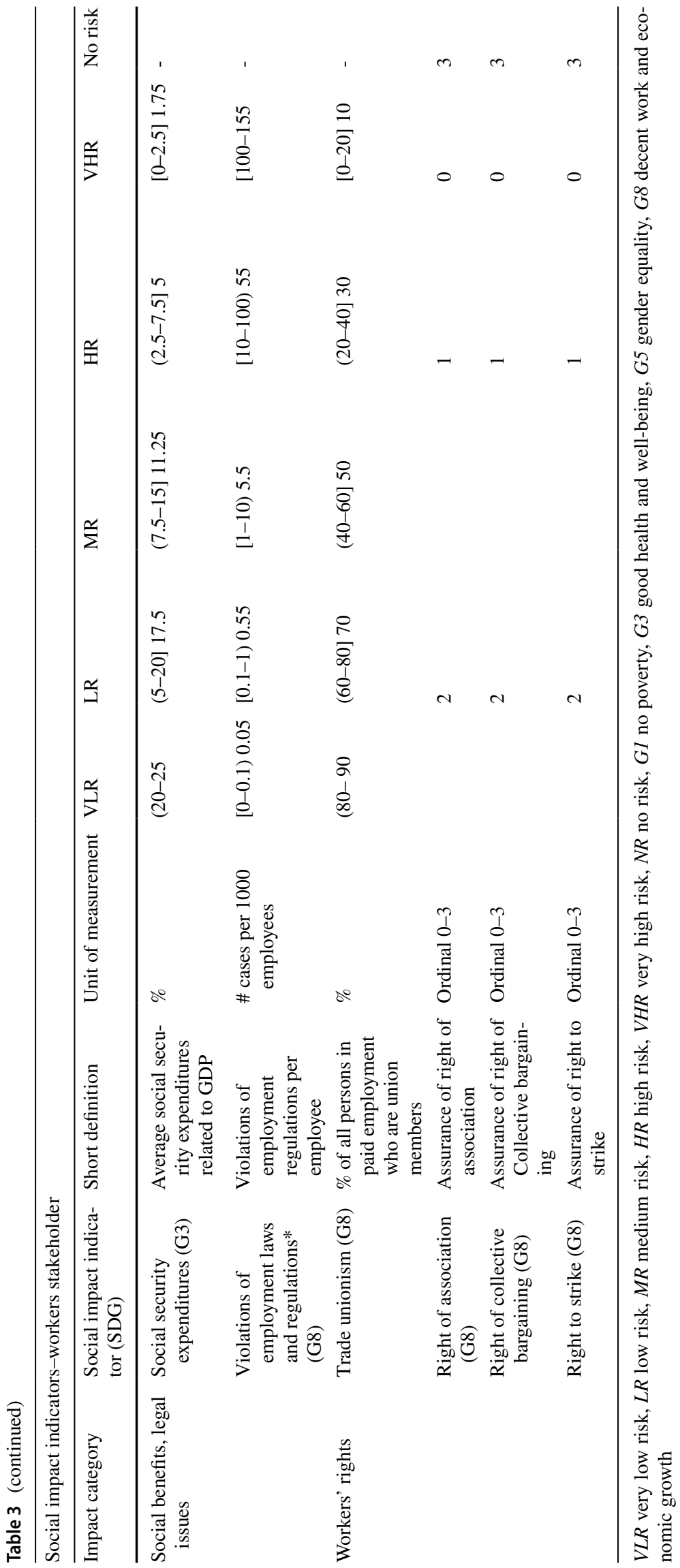




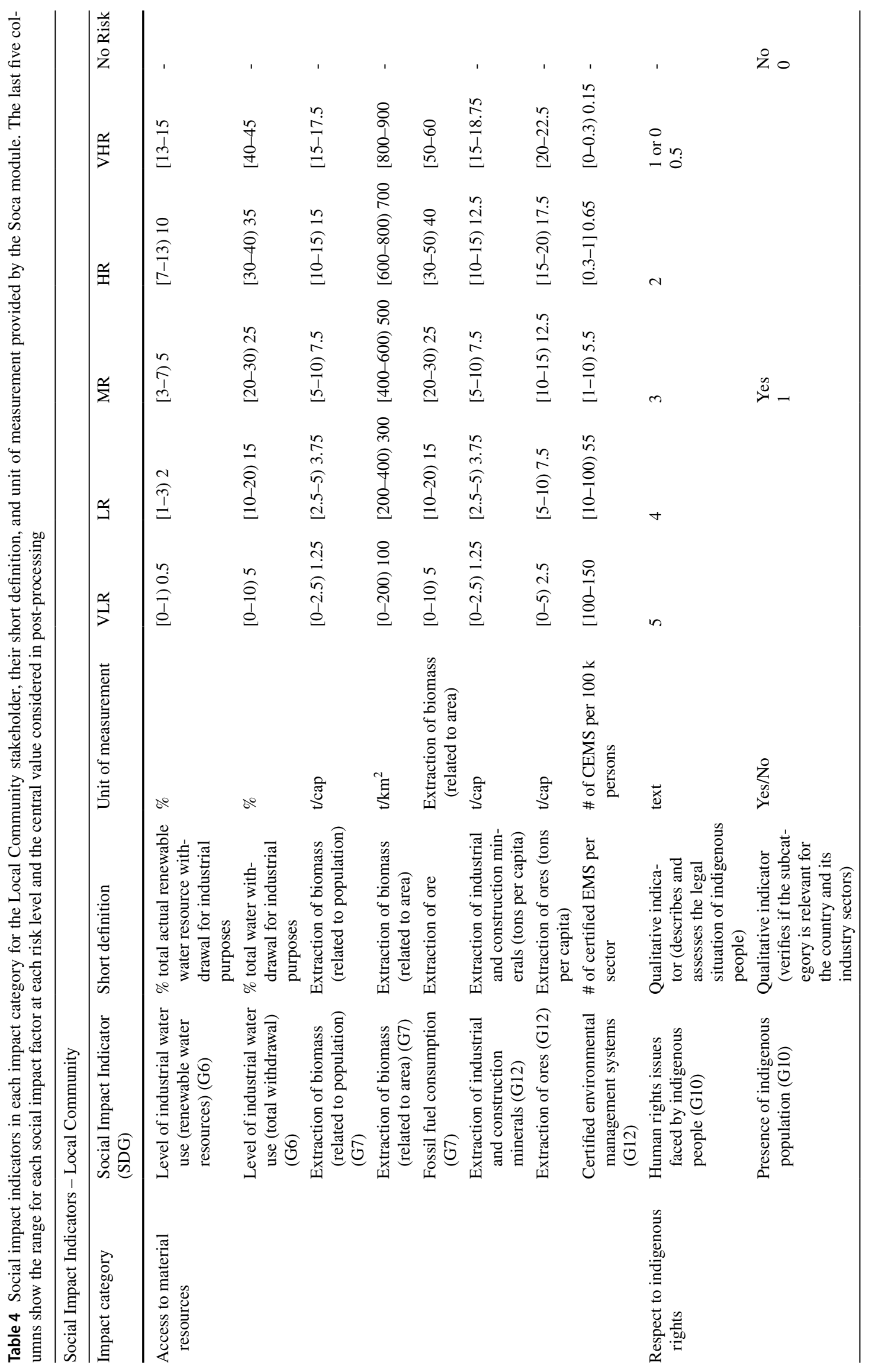




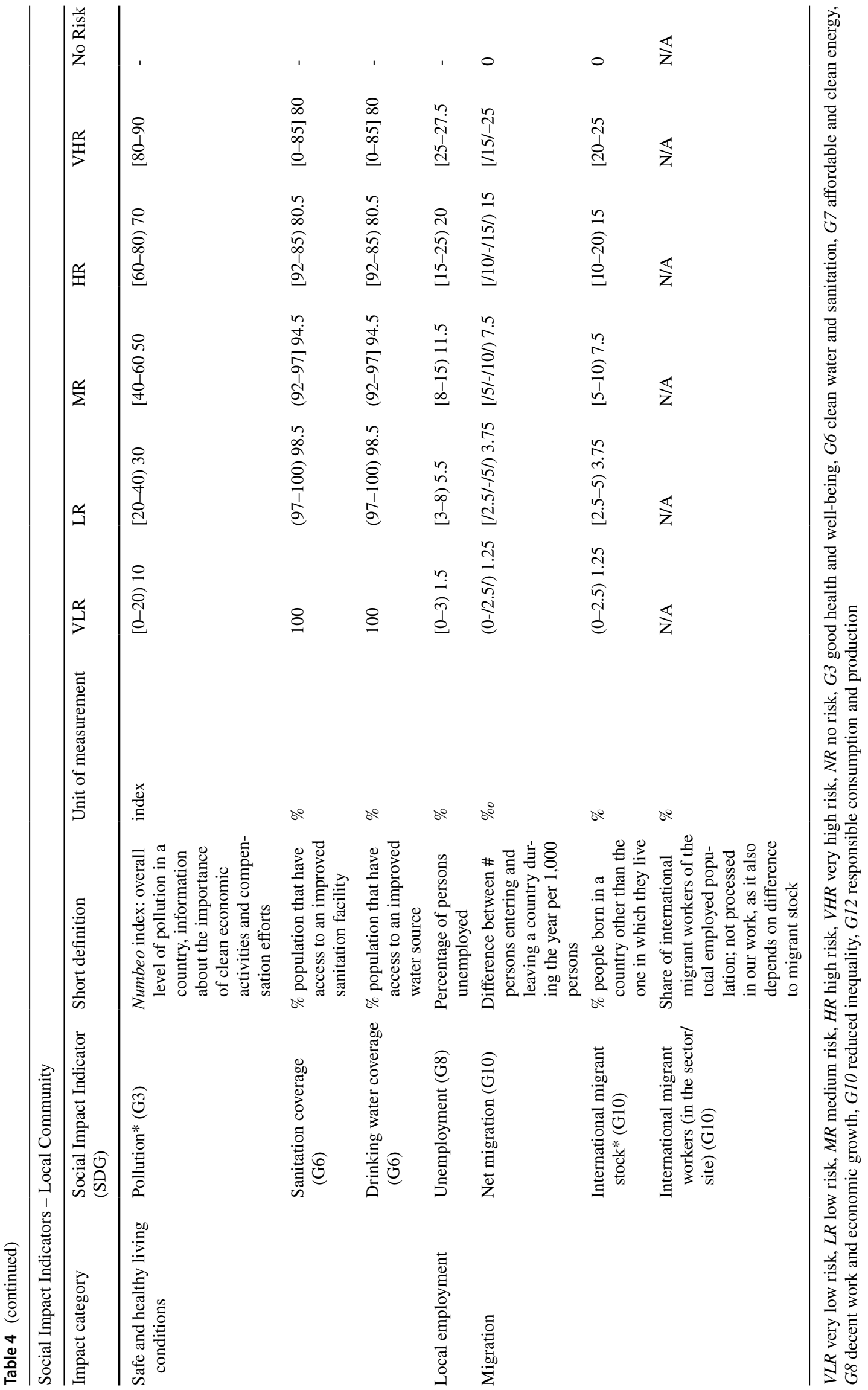


Table 5 Social impact indicators in each impact category for the Society stakeholder, their short definition, and unit of measurement provided by the Soca module. The last five columns show the range for each social impact factor at each risk level and the central value considered in post-processing

\begin{tabular}{|c|c|c|c|c|c|c|c|c|c|}
\hline \multicolumn{10}{|c|}{ Social Impact Indicators - Society } \\
\hline $\begin{array}{l}\text { Impact cat- } \\
\text { egory }\end{array}$ & $\begin{array}{l}\text { Social Impact } \\
\text { Indicator } \\
\text { (SDG) }\end{array}$ & Short definition & $\begin{array}{l}\text { Unit of } \\
\text { measure- } \\
\text { ment }\end{array}$ & VLR & LR & MR & $\mathrm{H}$ & VHR & No Risk \\
\hline \multirow[t]{7}{*}{$\begin{array}{l}\text { Contribution } \\
\text { to economic } \\
\text { development }\end{array}$} & $\begin{array}{l}\text { Public } \\
\text { expenditure } \\
\text { on education } \\
\text { (G4) }\end{array}$ & $\begin{array}{l}\text { Public expenditure } \\
\text { on education as \% } \\
\text { of GDP }\end{array}$ & $\%$ & {$[10-12.5$} & {$[7.5-10) 8.75$} & {$[5-7.5) 6.25$} & {$[2.5-5) 3.75$} & {$[0-2.5) 1.25$} & - \\
\hline & $\begin{array}{r}\text { Illiteracy rate, } \\
\text { female (G4) }\end{array}$ & $\begin{array}{l}\text { Average } \% \text { of } \\
\text { female popula- } \\
\text { tion }>15 \text { years that } \\
\text { cannot correctly } \\
\text { read nor write }\end{array}$ & $\%$ & [0-1) 0.5 & {$[1-4) 2.5$} & [4-8) 6 & [8-15) 11.5 & {$[15-25$} & - \\
\hline & $\begin{array}{l}\text { Illiteracy rate, } \\
\text { male (G4) }\end{array}$ & $\begin{array}{l}\text { Average } \% \text { of } \\
\text { male popula- } \\
\text { tion }>15 \text { years that } \\
\text { cannot correctly } \\
\text { read nor write }\end{array}$ & $\%$ & [0-1) 0.5 & {$[1-4) 2.5$} & [4-8) 6 & [8-15) 11.5 & {$[15-25$} & \\
\hline & $\begin{array}{c}\text { Illiteracy rate, } \\
\text { total*(G4) }\end{array}$ & $\begin{array}{l}\text { Average } \% \text { of popula- } \\
\text { tion }>15 \text { years that } \\
\text { cannot correctly } \\
\text { read nor write }\end{array}$ & $\%$ & [0-1) 0.5 & {$[1-4) 2.5$} & {$[4-8) 6$} & [8-15) 11.5 & {$[15-25$} & \\
\hline & $\begin{array}{l}\text { Youth illit- } \\
\text { eracy rate, } \\
\text { female (G4) }\end{array}$ & $\begin{array}{l}\text { Average } \% \text { of } \\
\text { female population } \\
15-24 \text { years that } \\
\text { cannot correctly } \\
\text { read nor write }\end{array}$ & $\%$ & [0-1) 0.5 & [1-4) 2.5 & [4-8) 6 & [8-15) 11.5 & {$[15-25$} & \\
\hline & $\begin{array}{l}\text { Youth illit- } \\
\text { eracy rate, } \\
\text { male (G4) }\end{array}$ & $\begin{array}{l}\text { Average } \% \text { of } \\
\text { male population } \\
15-24 \text { years that } \\
\text { cannot correctly } \\
\text { read nor write }\end{array}$ & $\%$ & [0-1) 0.5 & {$[1-4) 2.5$} & {$[4-8) 6$} & [8-15) 11.5 & {$[15-25$} & \\
\hline & $\begin{array}{l}\text { Youth illit- } \\
\text { eracy rate, } \\
\text { total (G4) }\end{array}$ & $\begin{array}{l}\text { Average \% of popu- } \\
\text { lation } 15-24 \text { years } \\
\text { that cannot } \\
\text { correctly read nor } \\
\text { write }\end{array}$ & $\%$ & [0-1) 0.5 & [1-4) 2.5 & {$[4-8) 6$} & {$[8-15) 11.5$} & {$[15-25$} & \\
\hline \multirow[t]{4}{*}{$\begin{array}{l}\text { Health and } \\
\text { Safety }\end{array}$} & $\begin{array}{l}\text { Health } \\
\quad \text { expenditure, } \\
\text { external } \\
\text { resources } \\
\text { (G3) }\end{array}$ & $\begin{array}{l}\text { External resources } \\
\text { for health as \% of } \\
\text { the total health } \\
\text { expenditure }\end{array}$ & $\%$ & {$[0-2.5) 1.25$} & {$[2.5-5) 3.75$} & {$[5-10) 7.5$} & {$[10-15) 12.5$} & {$[15-17.5$} & - \\
\hline & $\begin{array}{l}\text { Health } \\
\text { expenditure, } \\
\text { out-of- } \\
\text { pocket (G3) }\end{array}$ & $\begin{array}{l}\text { Out-of-pocket health } \\
\text { expenditure as } \% \\
\text { of the total health } \\
\text { expenditure }\end{array}$ & $\%$ & {$[0-10) 5$} & {$[10-20) 15$} & {$[20-35) 27.5$} & {$[35-50) 42.5$} & {$[50-57$} & \\
\hline & $\begin{array}{l}\text { Health } \\
\text { expenditure, } \\
\text { public (G3) }\end{array}$ & $\begin{array}{l}\text { Sum of public health } \\
\text { expenditure as \% } \\
\text { of the total health } \\
\text { expenditure }\end{array}$ & $\%$ & {$[80-90$} & {$[60-80) 70$} & {$[40-6050$} & {$[20-40) 70$} & {$[0-20] 10$} & - \\
\hline & $\begin{array}{l}\text { Health } \\
\text { expenditure, } \\
\text { total (G3) }\end{array}$ & $\begin{array}{l}\text { Sum of public and } \\
\text { private health } \\
\text { expenditure as \% } \\
\text { of GDP }\end{array}$ & $\%$ & {$[15-25$} & {$[10-15) 12.5$} & {$[5-10) 7.5$} & {$[2.5-5) 3.75$} & $0-2.5) 1.25$ & \\
\hline
\end{tabular}

$V L R$ very low risk, $L R$ low risk, $M R$ medium risk, $H R$ high risk, $V H R$ very high risk, $N R$ no risk, $G 3$ good health and well-being, $G 4$ quality education

brackets) and indirect impacts (without brackets). The latter are the results comparable to the reference values. The direct impacts are obtained for the following indicators: frequency of forced labour, fatal accidents, non-fatal accidents, safety measures and violations of employment laws and regulations.

By comparing the reference value with the result obtained for each of the social impact indicators, it is possible to 
characterise the socio-economic context that supports the academic activity of the UPV/EHU. In relation to the Workers stakeholder, 18 out of the 21 social impacts calculated remain at the same level of risk. However, the risk levels associated with the results of the child labour impact category, i.e. child labour, male and child labour, total, and the social impacts of the minimum wage in the fair salary impact category are higher than the corresponding reference values. This is because some of the processes involved in the supply of energy or materials to the academic activity of the UPV/ EHU are located in countries where the level of risk associated with these social impacts is higher than in the ACBC.

Table 8 shows the social impact of the UPV/EHU academic activity for the Local Community stakeholder. The level of associated risk for 14 of the 17 social impact indicators is very low (3), low (5), or medium (6). The social impact indicators for international migrant population and unemployment present a high and very high risk respectively. No data are available on the social impact of international migrant workers (at sector/site level). Furthermore, for all impact categories, there are social impact indicators that present a higher level of risk associated with the academic activity of the UPV/EHU than the reference value. For example, for the impact categories Access to material resources: extraction of biomass (related to population) and extraction of industrial and construction minerals present higher risk levels than in the ACBC (Eustat 2020).

Social impact results of UPV/EHU academic activity for the Society stakeholder gathered in Table 9 show that just 1 out of 11 social impact indicators presents a High Risk level, i.e. Public expenditure on education, whereas the level of associated risk for the other 10 social impact indicators is very low (1), low (4), or medium (5). In the case of Health and Safety impact category, if the level of risk associated with the reference value and the result obtained by S-LCA are compared, the level of risk is maintained for all indicators. However, in the Contribution to economic development category, the level of risk associated with the result obtained by SO-LCA is greater than that associated with the reference value for all the indicators. Therefore, part of the processes involved in the supply of energy and materials to the academic activity of UPV/EHU are located in countries where (1) public expenditure as \% of GDP on education is lower than in the ACBC, and (2) \% of population older than 15 years old that cannot correctly read or write is greater than in the ACBC.

Table 10 presents the results of the two impact categories that describe the stakeholder category Value Chain Actors. For the three social impact indicators, the level of associated risk is very low (1), low (1), or medium (1). Anti-competitive behaviour or violation of anti-trust and monopoly legislation displays the lowest level of associated risk and public sector corruption displays the highest level. In general, for 
Table 7 Social impact results and corresponding risk level in each impact category for the Workers stakeholder

Social impact results and corresponding risk level—Workers stakeholder

\begin{tabular}{|c|c|c|c|c|}
\hline Impact category & Social impact indicator (SDG) & Reference value ${ }^{\mathrm{x}, \mathrm{y}}$ & Result $^{y}$ & $\begin{array}{l}\text { Risk level in relation } \\
\text { to reference value risk } \\
\text { level }\end{array}$ \\
\hline \multirow[t]{3}{*}{ Child labour } & Child Labour, female (G8) & $0^{2, \mathrm{a}}$ & $2.45^{\mathrm{a}}$ & $\equiv$ \\
\hline & Child Labour, male (G8) & $0^{2, \mathrm{a}}$ & $2.80^{\mathrm{b}}$ & $\uparrow$ \\
\hline & Child Labour, total* (G8) & $0^{2, \mathrm{a}}$ & $2.76^{\mathrm{b}}$ & $\uparrow$ \\
\hline \multirow[t]{3}{*}{ Forced labour } & Frequency of forced labour (G8) & $1.5^{2, \mathrm{a}}$ & $1.42^{\mathrm{a}}\left(10.7^{\mathrm{a}}\right)$ & $\equiv$ \\
\hline & Goods produced by forced labour (G8) & $(0-10)$ (n.a.) & $0.09^{\mathrm{f}}$ & \\
\hline & Trafficking in persons (G8) & $1^{2, \mathrm{a}}$ & $1.2^{\mathrm{a}}$ & $\equiv$ \\
\hline \multirow[t]{3}{*}{ Fair salary } & Living wage (per month) (G1) & $727^{2, \mathrm{~d}}$ & $683^{\mathrm{d}}$ & $\equiv$ \\
\hline & Minimum wage (per month) (G1) & $803^{\mathrm{b}}$ & $394^{c}$ & $\uparrow$ \\
\hline & Sector average wage (per month) (G1) & $4.98^{0, \mathrm{a}}$ & $2.75^{\mathrm{a}}$ & $\equiv$ \\
\hline Working time & Weekly hours of work per employee (G8) & $36^{2, \mathrm{c}}$ & $36.3^{\mathrm{c}}$ & $\equiv$ \\
\hline Discrimination & Gender wage gap* (G5) & $24.3^{2, \mathrm{~d}}$ & $23.4^{\mathrm{d}}$ & $\equiv$ \\
\hline \multirow[t]{5}{*}{ Health and safety } & Fatal accidents* (G8) & $2.19^{1, \mathrm{a}}$ & $10^{\mathrm{a}}\left(0.75^{\mathrm{a}}\right)$ & $\equiv$ \\
\hline & Non-fatal accidents* (G8) & $1,719^{1, \mathrm{c}}$ & $1,963^{\mathrm{c}}\left(147.46^{\mathrm{c}}\right)$ & $\equiv$ \\
\hline & $\begin{array}{l}\text { DALYs due to indoor and outdoor air and water } \\
\text { pollution (G3) }\end{array}$ & $2.86^{2, \mathrm{a}}$ & $4.48^{\mathrm{a}}(33.7)$ & $\equiv$ \\
\hline & Safety measures* (G3) & $21.43^{2, \mathrm{a}}$ & $89.3^{\mathrm{a}}\left(67.1^{\mathrm{a}}\right)$ & $\equiv$ \\
\hline & Workers affected by natural disasters (G3) & $0^{2, \mathrm{a}}$ & $0.95^{\mathrm{a}}$ & $\equiv$ \\
\hline \multirow[t]{2}{*}{ Social benefits, legal issues } & Social security expenditures (G3) & $15.28^{2, \mathrm{~b}}$ & $15.3^{\mathrm{b}}$ & $\equiv$ \\
\hline & $\begin{array}{l}\text { Violations of employment laws and regulations* } \\
\text { (G8) }\end{array}$ & $17.96^{2, \mathrm{~d}}$ & $44.7^{\mathrm{d}}\left(336^{\mathrm{d}}\right)$ & $\equiv$ \\
\hline \multirow[t]{4}{*}{ Workers' rights } & Trade unionism (G8) & $22.1^{2, \mathrm{~d}}$ & $29.9^{\mathrm{d}}$ & $\equiv$ \\
\hline & Right of association (G8) & $3^{2, \mathrm{f}}$ & $2.96^{\mathrm{f}}$ & $\equiv$ \\
\hline & Right of Collective bargaining (G8) & $3^{2, \mathrm{f}}$ & $2.95^{\mathrm{f}}$ & $\equiv$ \\
\hline & Right to Strike (G8) & $3^{2, \mathrm{f}}$ & $2.93^{\mathrm{f}}$ & $\equiv$ \\
\hline
\end{tabular}

$\{\mathrm{x}: 0=\mathrm{UPV} / \mathrm{EHU}$ (UPV/EHU 2020b), $1=$ Autonomous Community of the Basque Country (Eustat 2020), 2=Spain $\} ;\{\mathrm{y}: \mathrm{a}=\mathrm{VLR}, \mathrm{b}=\mathrm{LR}$, $\mathrm{c}=\mathrm{MR}, \mathrm{d}=\mathrm{HR}, \mathrm{e}=\mathrm{VHR}, \mathrm{f}=\mathrm{NR}\} ;\{\equiv$ : same risk level for result and reference value; $\uparrow:$ risk level of result higher than that of reference value; $\downarrow$ : risk level of result lower than that of reference value risk level\}

the fair competition and corruption impact categories, the level of risk calculated for the academic activity of the UPV/ EHU with respect to the reference value remains the same. As in Table 7, a direct impact has also been estimated here, i.e. for fair competition ( 0.026 enforcement cases in a year).

The results column in Tables 7, 8, 9, and 10 shows the levels of social risk obtained by each Social Impact Indicator and is represented by superscript $y$, which, as specified above, ranges between very low risk to very high risk or no risk. Furthermore, as each social impact indicator has previously been linked to an SDG, it follows that those Social Impact Indicators presenting a higher social risk level are related to SDGs 1, 4, 5, 8, and 10. For SGD1 (No Poverty), the social indicators presenting higher social risks are associated with living wage (per month) and sector average wage (per month). For Quality Education (SDG4), the highest risk level is associated with education expenditure. In SDG5 (Gender Equality) the gender wage gap Soca indicator shows a very high risk level. The main risks for Decent
Work and Economic Growth (SDG 8) are related to a high level of unemployment together with violations of employment laws and regulations and trade unionism density rate. For Reduced Inequality (SDG10), the main risk is related to international migrant stock.

The modelling, using openLCA and Soca, of the various flows of energy and material consumption, waste generation, and transport needs, allows a disaggregated analysis of social impacts (for extended documentation on the modelling, see the dataset article (Bueno G, de Blas M, Pérez-Iribarren E et al. Dataset on the environmental and social footprint of the University of the Basque Country UPV/EHU, Unpublished work). Figures 2 and 3 show the relative contribution of activity hours, weighted by risk level, in relation to Transport, Energy and Materials Consumption, Waste Treatment and Labour Activity in the UPV/EHU, for each of the 11 selected social impact categories for disaggregated analysis, including the cost estimation of the UPV/EHU's academic activity. As a reference, the first column in both figures shows 
Table 8 Social impact results and corresponding risk level in each impact category for the Local Community stakeholder Social impact results-local community

\begin{tabular}{|c|c|c|c|c|}
\hline Impact category & Social impact indicator (SDG) & Reference value $\mathrm{e}^{\mathrm{x}, \mathrm{y}}$ & Result $^{y}$ & $\begin{array}{l}\text { Risk level in relation } \\
\text { to reference value risk } \\
\text { level }\end{array}$ \\
\hline \multirow[t]{8}{*}{ Access to material resources } & $\begin{array}{l}\text { Level of industrial water use (renewable water } \\
\text { resources) (G6) }\end{array}$ & $5.92^{2, \mathrm{c}}$ & $4.92^{\mathrm{c}}$ & $\equiv$ \\
\hline & Level of industrial water use (total withdrawal) (G6) & $55.12^{1, \mathrm{e}}$ & $24.86^{\mathrm{c}}$ & $\downarrow$ \\
\hline & Extraction of biomass (related to population) (G7) & $1.45^{1, \mathrm{a}}$ & $3.75^{\mathrm{b}}$ & $\uparrow$ \\
\hline & Extraction of biomass (related to area) (G7) & $435.71^{1, \mathrm{c}}$ & $465.71^{\mathrm{c}}$ & $\equiv$ \\
\hline & Fossil fuel consumption $(\mathrm{G} 7)$ & $0^{1, \mathrm{a}}$ & $6.57^{\mathrm{a}}$ & $\equiv$ \\
\hline & $\begin{array}{l}\text { Extraction of industrial and construction minerals } \\
\text { (G12) }\end{array}$ & $4.02^{1, \mathrm{~b}}$ & $7.18^{\mathrm{c}}$ & $\uparrow$ \\
\hline & Extraction of ores (G12) & $0^{1, \mathrm{a}}$ & $2.55^{\mathrm{a}}$ & $\equiv$ \\
\hline & Certified environmental management system (G12) & $15.07^{2, \mathrm{~b}}$ & $\begin{array}{l}45.36^{\mathrm{b}} \\
(34.10)\end{array}$ & $\equiv$ \\
\hline \multirow[t]{2}{*}{ Respect to indigenous rights } & $\begin{array}{l}\text { Human rights issues faced by indigenous people } \\
\text { (G10) }\end{array}$ & $4^{2, \mathrm{~b}}$ & $4^{\mathrm{b}}$ & $\equiv$ \\
\hline & Presence of indigenous population (G10) & $\mathrm{N}^{1, \mathrm{f}}$ & $\mathrm{Y}^{\mathrm{c}}$ & $\uparrow$ \\
\hline \multirow[t]{3}{*}{ Safe and healthy living conditions } & Pollution* (G3) & $31.98^{1, \mathrm{~b}}$ & $51.61^{\mathrm{c}}$ & $\uparrow$ \\
\hline & Sanitation coverage (G6) & $99.9^{2, \mathrm{a}}$ & $95.32^{\mathrm{c}}$ & $\uparrow \uparrow$ \\
\hline & Drinking water coverage (G6) & $100^{2, \mathrm{a}}$ & $98.08^{\mathrm{b}}$ & $\uparrow$ \\
\hline Local employment & Unemployment (G8) & $13.4^{1, \mathrm{c}}$ & $24.06^{\mathrm{e}}$ & $\uparrow \uparrow$ \\
\hline \multirow[t]{3}{*}{ Migration } & Net migration (G10) & $4.08^{1, \mathrm{~b}}$ & $6.29^{\mathrm{c}}$ & $\uparrow$ \\
\hline & International migrant stock* (G10) & $8.76^{1, \mathrm{c}}$ & $14.96^{\mathrm{d}}$ & $\uparrow$ \\
\hline & $\begin{array}{l}\text { International migrant workers (in the sector/site) } \\
\text { (G10) }\end{array}$ & $11.89^{1, \text { n.a }}$ & n.a & \\
\hline
\end{tabular}

\{x: 0=UPV/EHU, $1=$ Autonomous Community of the Basque Country (Eustat 2020; Numbeo 2020; URA 2020), 2=Spain $\} ;\{y: a=$ VLR, $\mathrm{b}=\mathrm{LR}, \mathrm{c}=\mathrm{MR}, \mathrm{d}=\mathrm{HR}, \mathrm{e}=\mathrm{VHR}, \mathrm{f}=\mathrm{NR}, \mathrm{n} . \mathrm{a} .=$ non available $\} ;\{\equiv$ : same risk level for result and reference value; $\downarrow$ : risk level of result one level lower than that of reference value; $\uparrow:$ risk level of the result one level higher than that of reference value; $\uparrow \uparrow:$ risk level of the result two levels higher than that of reference value\}

the contribution of activity hours in each of these sub-processes (Labour Activity at the UPV/EHU, Materials Consumption, Energy Consumption, Waste Treatment, and Transport). Labour activity in the UPV/EHU constitutes nearly $80 \%$ of total activity hours. In particular, Fig. 2 shows the disaggregated analysis for direct social impact categories, i.e. impacts with a strong causal relation with the academic activity of the UPV/EHU (fatal accidents, non-fatal accidents, employment law and regulation violations, safety measure violations, anti-competitive behaviour cases, and economic costs). In addition, Fig. 3 shows the disaggregated analysis of other selected indirect social impact categories that provide information about the socio-economic context that supports the academic activity under assessment (child labour, gender wage gap, social perception of pollution, international migrant stock, and illiteracy rate).

The labour activity at the UPV/EHU is the most significant sub-process, in terms of impacts, for 7 out of the 11 social impact indicators analysed and represented in Figs. 2 and 3. In regard to direct social impacts, for example, it gives rise to more than $93 \%$ of the estimation for the UPV/EHU academic activity's economic costs, and around $98 \%$ of the employment law and regulation violations (Fig. 2). This last result may be related to the fact that law regulation is rather strict in the ACBC, resulting in fewer violations of employment laws in the rest of flows supporting the academic activity of the UPV/EHU. By contrast, for fatal accidents and safety measure violations, transport is a more significant subprocess, as it gives rise to around $40 \%$ of the total impact. This reveals the importance of transport in the generation of unwanted impacts, especially with regard to fatal accidents. The environmental impacts generated by the transportation needs supporting the academic activity of the UPV/EHU, as well as the ways to address them, are approached in detail by Zuazo et al. (Zuazo I, Torre-Pascual E, Bueno G et al. The environmental footprint of the mobility needs of the University of the Basque Country UPV/EHU, Unpublished).

Figure 3 reflects the significance of Labour activity in the UPV/EHU in terms of indirect social impacts, with three of them exceeding $76 \%$ (gender wage gap, pollution, international migrant stock). In contrast, the contribution of the UPV/EHU labour activity to the impact on the illiteracy rate is considerably lower (34\%), and barely significant in the child labour category $(3.5 \%)$. Thus, it can be concluded 
Table 9 Social impact results and corresponding risk level in each impact category for the Society stakeholder

Social impact results-society

\begin{tabular}{|c|c|c|c|c|}
\hline Impact category & Social impact indicator & Reference value ${ }^{\mathrm{x}, \mathrm{y}}$ & Result $^{\mathrm{y}}$ & $\begin{array}{l}\text { Risk level in relation } \\
\text { to reference value risk } \\
\text { level }\end{array}$ \\
\hline \multirow{7}{*}{$\begin{array}{l}\text { Contribution to economic } \\
\text { development }\end{array}$} & Public expenditure on education (G4) & $5^{1, \mathrm{c}}$ & $3.85^{\mathrm{d}}$ & $\uparrow$ \\
\hline & Illiteracy rate, female (G4) & $0.48^{1, \mathrm{a}}$ & $5.98^{\mathrm{c}}$ & $\uparrow \uparrow$ \\
\hline & Illiteracy rate, male (G4) & $0.23^{1, \mathrm{a}}$ & $4.18^{\mathrm{c}}$ & $\uparrow \uparrow$ \\
\hline & Illiteracy rate, total* $(\mathrm{G} 4)$ & $0.36^{1, \mathrm{a}}$ & $5.84^{\mathrm{c}}$ & $\uparrow \uparrow$ \\
\hline & Youth illiteracy rate, female (G4) & $0^{1, \mathrm{a}}$ & $2.25^{\mathrm{b}}$ & $\uparrow$ \\
\hline & Youth illiteracy rate, male (G4) & $0^{1, \mathrm{a}}$ & $2.2^{\mathrm{b}}$ & $\uparrow$ \\
\hline & Youth illiteracy rate, total (G4) & $0^{1, \mathrm{a}}$ & $2.22^{\mathrm{b}}$ & $\uparrow$ \\
\hline \multirow[t]{4}{*}{ Health and safety } & Health expenditure, external resources (G3) & $0^{1, \mathrm{a}}$ & $1.97^{\mathrm{a}}$ & $\equiv$ \\
\hline & Health expenditure, out-of-pocket (G3) & $29.73^{1, c}$ & $27.87^{\mathrm{c}}$ & $\equiv$ \\
\hline & Health expenditure, public (G3) & $70.27^{1, b}$ & $67^{\mathrm{b}}$ & $\equiv$ \\
\hline & Health expenditure, total (G3) & $8.7^{1, \mathrm{c}}$ & $7.54^{\mathrm{c}}$ & $\equiv$ \\
\hline
\end{tabular}

$\{\mathrm{x}: 0=\mathrm{UPV} / \mathrm{EHU}, 1=$ Autonomous Community of the Basque Country (Eustat 2020), $2=$ Spain $\} ;\{\mathrm{y}: \mathrm{a}=\mathrm{VLR}, \mathrm{b}=\mathrm{LR}, \mathrm{c}=\mathrm{MR}, \mathrm{d}=\mathrm{HR}$, $\mathrm{e}=\mathrm{VHR}, \mathrm{f}=\mathrm{NR}\} ;\{\equiv$ : same risk level for result and reference value; $\uparrow:$ risk level of result higher than that of reference value; $\downarrow:$ risk level of result lower than that of reference value risk level\}

that the socio-economic context that supports the academic activity of the UPV/EHU outside its labour activity, shows traces of illiteracy and, above all, child labour. Transport is also the most prominent sub-process in this regard, representing $40.4 \%$ of the impact on illiteracy rate and $53.1 \%$ of the impact on child labour.

Figures 4 and 5 provide a similar disaggregated analysis for the location of the social impacts derived from the academic activity of the UPV/EHU for the selected social impact categories and for the estimation of economic costs. These have been grouped as they are located: within the ACBC (labelled as Basque Country in Figs. 4 and 5), outside the ACBC, or in locations not defined according to the available information. In Figs. 4 and 5, the first column also serves as a reference, since it illustrates the location of activity hours, reflecting that nearly $80 \%$ are located in the ACBC. In fact, for the seven social impact categories where labour activity at the UPV/EHU is the most considerable sub-process according to Figs. 2 and 3, the impact is located mostly in the ACBC. However, for the other four social impact categories, at least $50 \%$ of the impact's location is not defined.

Regarding direct social impacts, Fig. 4 shows that economic costs and employment law and regulation violations are located in the ACBC almost entirely, while for fatal accidents and safety measure violations, the location is largely undefined, with $65 \%$ and $49 \%$ respectively. This result is consistent with that shown in Fig. 2, as it indicates the lower relative importance of activity hours for both impacts and thus its smaller occurrence in the ACBC.

In a similar way, for the categories of indirect social impact, the results shown in Fig. 5 regarding geographical location are consistent with those shown in Fig. 3 regarding labour activity. On the one hand, almost $80 \%$ of pollution is located in the ACBC, whereas more than $80 \%$ of both gender wage gap and international migrant stock related impacts are located in the ACBC. Meanwhile, the location of the illiteracy rate is not defined at $55 \%$ and that of child labour at

Table 10 Social impact results and corresponding risk level in each impact category for the Value Chain Actors stakeholder

\begin{tabular}{|c|c|c|c|c|}
\hline \multicolumn{5}{|c|}{ Social impact results-value chain actors } \\
\hline Impact category & Social impact indicator & $\begin{array}{l}\text { Reference } \\
\text { value }^{\mathrm{x}, \mathrm{y}}\end{array}$ & $\operatorname{Result}^{\mathrm{y}}$ & $\begin{array}{l}\text { Risk level in relation } \\
\text { to reference value risk } \\
\text { level }\end{array}$ \\
\hline Fair competition & $\begin{array}{l}\text { Anti-competitive behaviour or violation of anti-trust and monopoly } \\
\text { legislation* (G16) }\end{array}$ & $0^{2, \mathrm{a}}$ & $0.034^{\mathrm{a}}\left(0.026^{\mathrm{a}}\right)$ & $\equiv$ \\
\hline \multirow[t]{2}{*}{ Corruption } & Active involvement of enterprises in corruption and bribery (G16) & $5^{2, \mathrm{~b}}$ & $6.19^{\mathrm{b}}$ & $\equiv$ \\
\hline & Public sector corruption (G16) & $65^{2, \mathrm{c}}$ & $67^{\mathrm{c}}$ & $\equiv$ \\
\hline
\end{tabular}

$\{\mathrm{x}: 0=\mathrm{UPV} / \mathrm{EHU}, 1=$ Autonomous Community of the Basque Country, $2=$ Spain $\} ;\{\mathrm{y}: \mathrm{a}=\mathrm{VLR}, \mathrm{b}=\mathrm{LR}, \mathrm{c}=\mathrm{MR}, \mathrm{d}=\mathrm{HR}, \mathrm{e}=\mathrm{VHR}, \mathrm{f}=\mathrm{NR}\}$; $\{\equiv:$ same risk level for result and reference value $\}$ 
Fig. 2 Relative contribution of activity hours, weighted by risk level, in relation to transportation, energy and material consumption, waste treatment, and labour activity in the UPV/ EHU for selected direct social impact categories

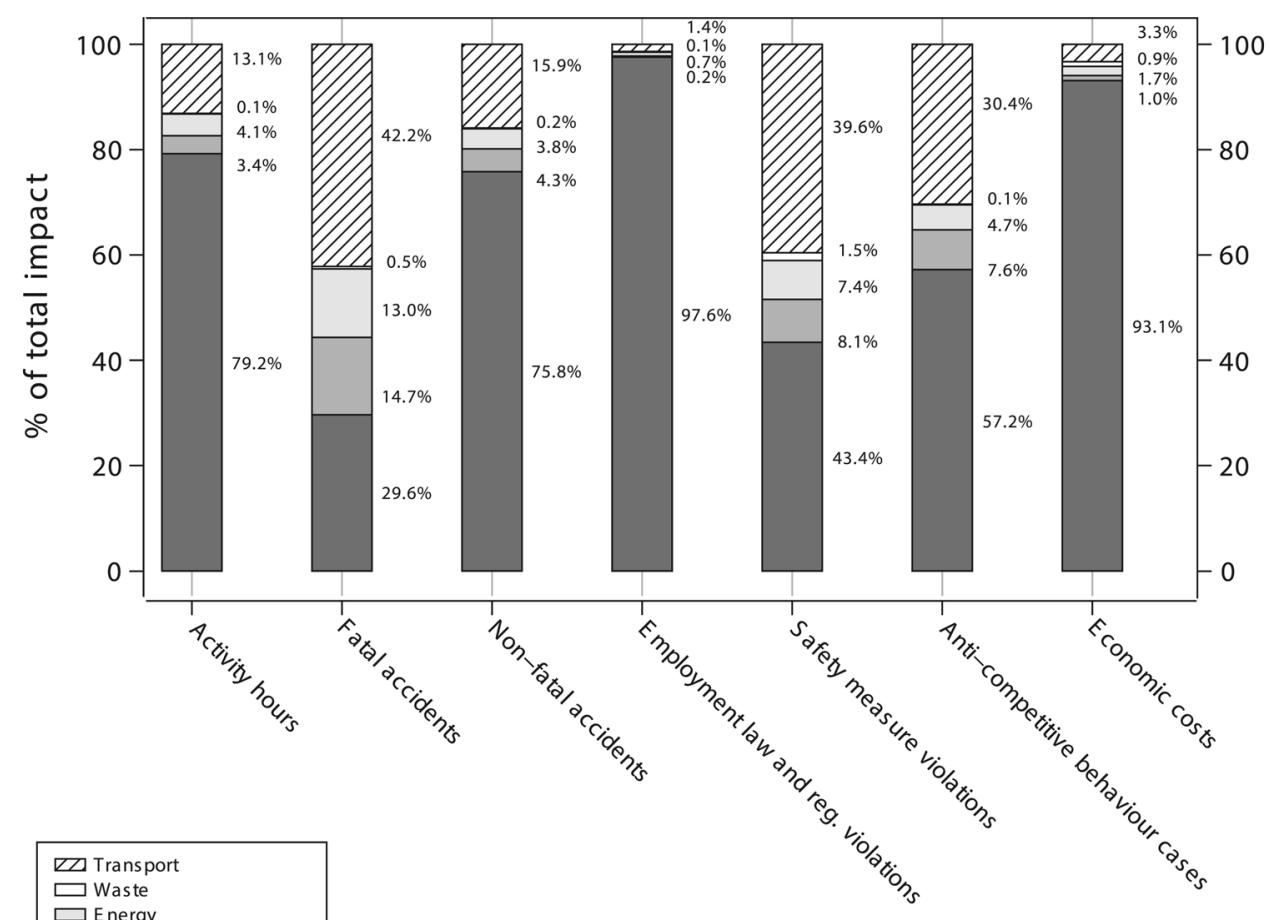

Direct social impact categories
96.9\%. Therefore, it seems that the traces of child labour and illiteracy detected in the socio-economic context that supports the academic activity of the UPV/EHU are located far outside the borders of the ACBC, although these are undefined locations. Further analysis would be needed to more precisely define the geographical location of these impacts.
Fig. 3 Relative contribution of activity hours, weighted by risk level, in relation to transportation, energy and material consumption, waste treatment, and labour activity at the UPV/ EHU for selected indirect social impact categories (providing information about the socioeconomic context)

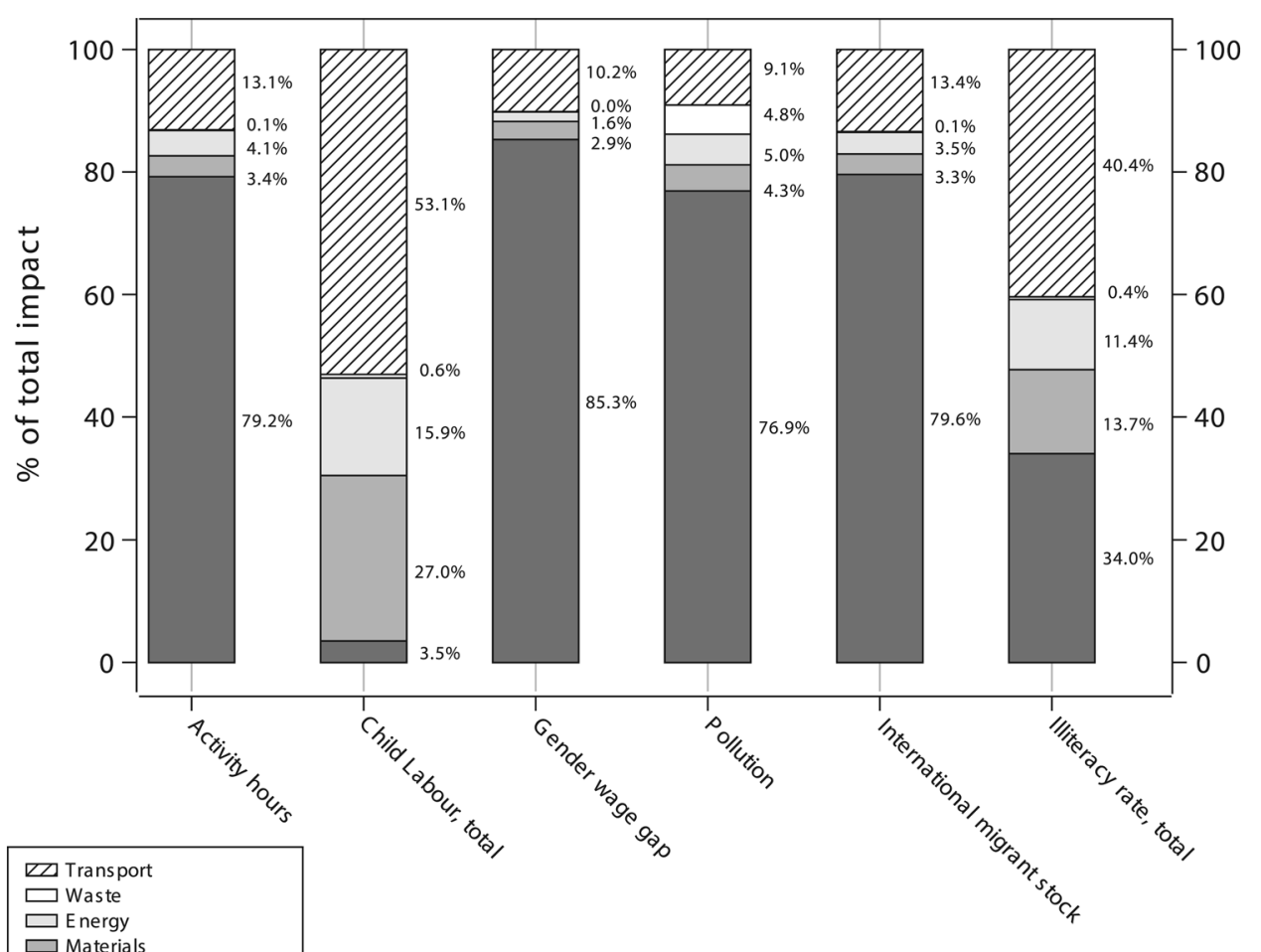

Indirect social impact categories 
Fig. 4 Relative contribution of activity hours, weighted by risk level, in relation to the location of the impact, for some selected direct social impact categories

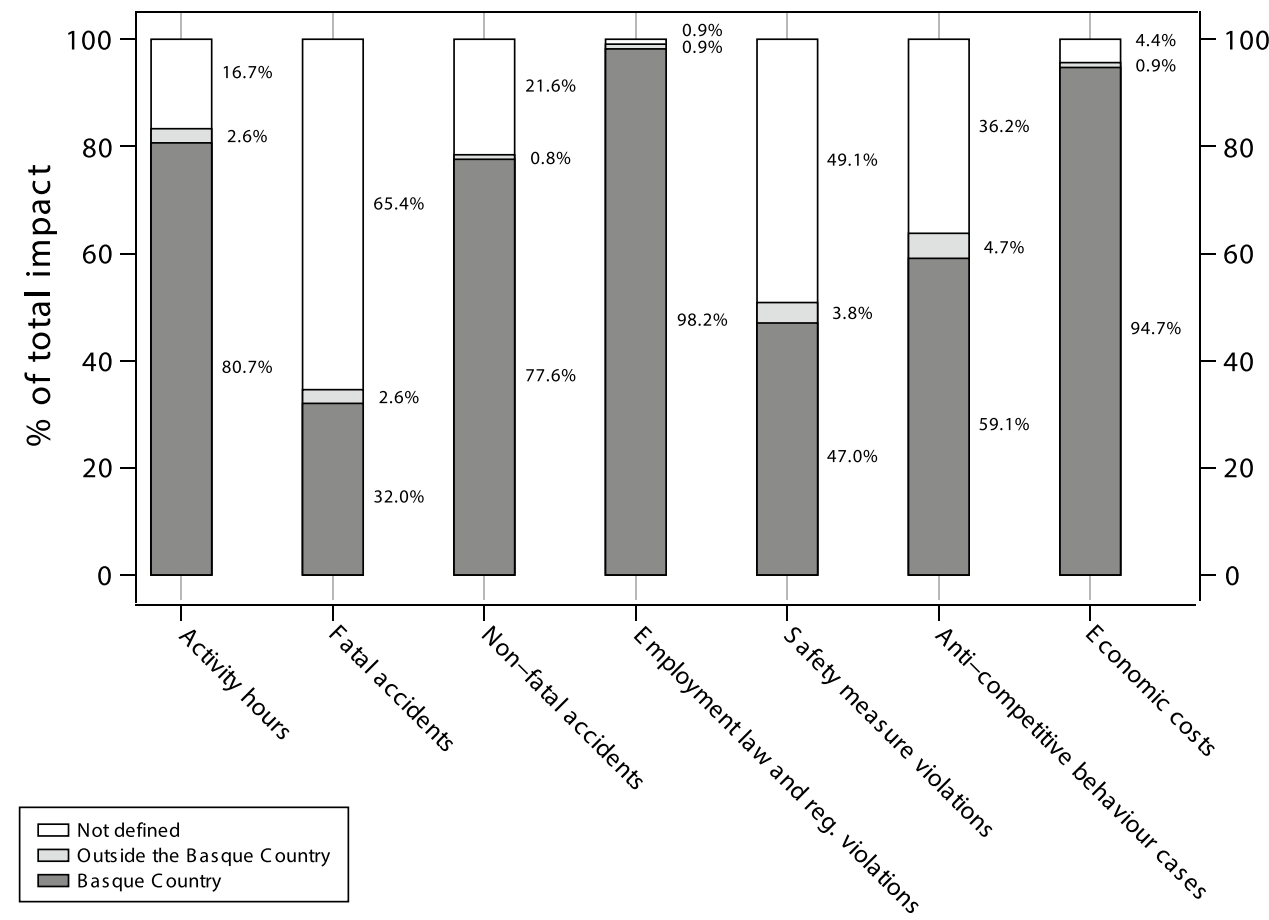

Direct social impact categories
With regard to the contribution to SDGs, the results indicate that for most of the Goals (SDG1, SDG3, SDG5, SDG7, SDG8, SDG12, SDG16), the risk level in the associated social impact indicators obtained with a life cycle perspective for the academic activity of the UPV/EHU is unchanged when compared to the risk level observed in the ACBC. All the indicators linked to SDG4 (Quality Education) and almost all those linked to SDG10 (Reduced
Fig. 5 Relative contribution of activity hours, weighted by risk level, in relation to the location of the impact, for selected indirect social impact categories (providing information about the socio-economic context)

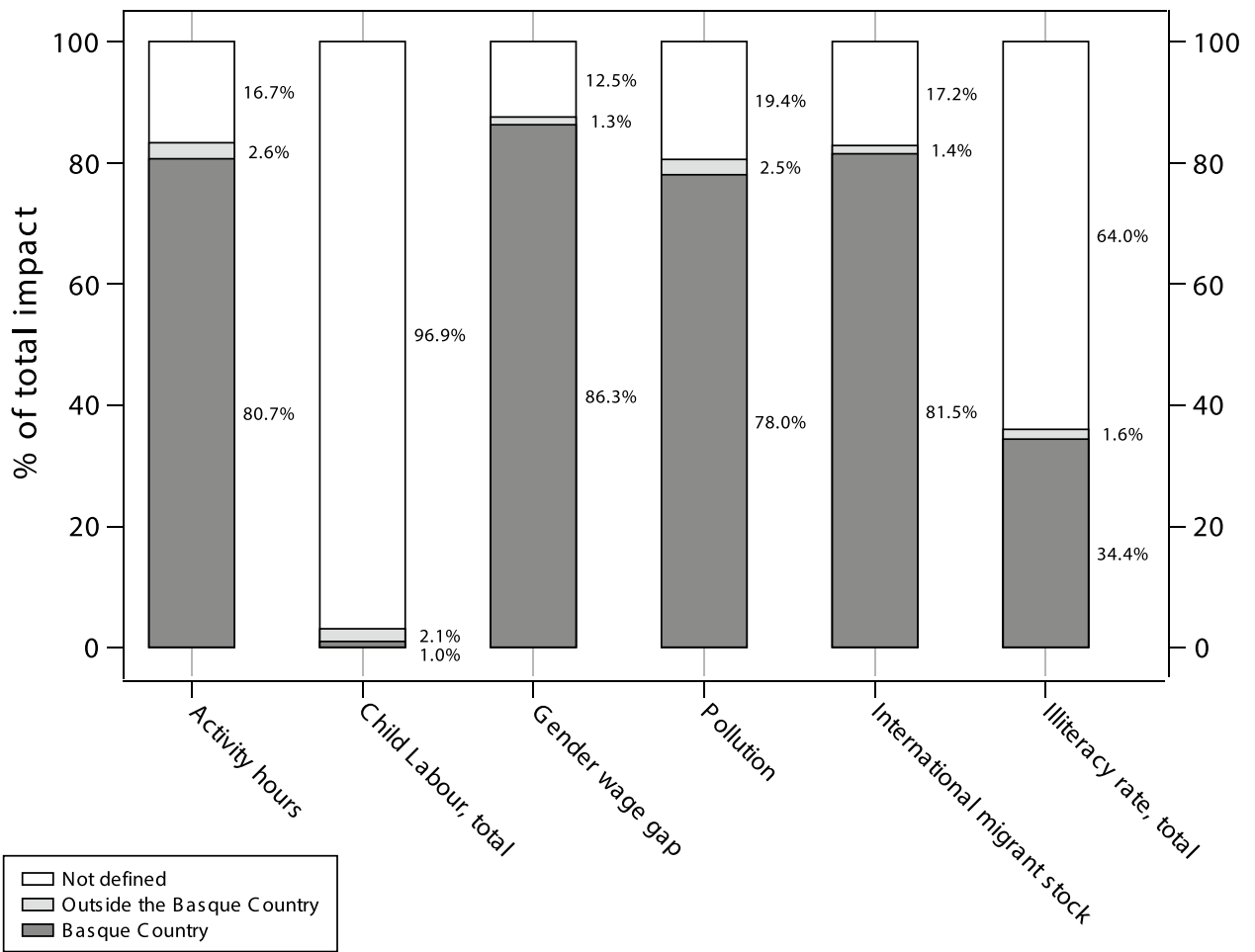

Indirect social impact categories 
Inequality) present a worse performance due to the fact that some activities in the life cycle of the academic activity of the UPV/EHU are carried out in sectors or countries with a worse performance than in the $\mathrm{ACBC}$ in the categories of contribution to economic development, respect to indigenous rights, and migration. A similar worsening behaviour is observed in indicators such as sanitation coverage and drinking water coverage (linked to SDG6), into the safe and healthy living conditions impact category. Furthermore, our study shows that some social impact indicators with medium or higher social risk levels in the ACBC, such us public expenditure on education (linked to SDG4), international migrant stock (SDG10), or unemployment (SDG8), also worsen their performance when the whole life cycle is considered: the obtained risk level is high for the first two indicators and very high for the last one. On the other hand, living wage (per month) (SDG1) and gender wage gap (SDG5) indicators maintain a high-risk level identical to the reference value, as expected given that for these indicators the social impacts are mainly located in the ACBC.

\section{Discussion}

The SO-LCA performed with the Soca add-on has enabled us to assess various social risks related to the academic activity of the UPV/EHU. Methodologically, the analysis carried out was based on a variant method that allows us to estimate the final aggregate social impacts in a more fitting way, without arbitrary risk level equivalences (see Sect. 2.1). However, the methodology applied still presents some challenges. On the one hand, the results shown are based in the social information gathered within the Soca add-on for Ecoinvent, based on the PSILCA database. Some impact categories have required approximations and adaptions. Specifically, data for the presence of sufficient safety measures are not country-specific but an extrapolation from data for US companies to suitable industry sectors worldwide (Ciroth and Eisfeldt 2016), or data for the child labour category are not sector-specific, as data for this category are collected at country level. The current limitations of such indicators should be taken into account when interpreting the results. On the other hand, the Soca database's backbone is EORA, i.e. the multi-regional input/output (MRIO) database, which harmonises different data sources covering the entire world economy, on an industrial sector basis. As a result, all processes and products within a country or region belonging to the same category are assigned the same social information. In addition, the information available through the Soca addon is expected to be completed gradually, thus increasing its accuracy and quality. In the same way, it would be very appropriate for Soca and the social LCIA method it uses, the Social Impact Weighting Method, to be completed in the future with indicators pertaining to the other two stakeholders (Consumers, Children) also proposed by the UNEP/ SETAC Guidelines (Benoît et al. 2020) and which are not yet considered in Soca.

This analysis has identified the processes that contribute most, from a life cycle approach, to the social footprint of the academic activity of the UPV/EHU. Although the main labour activity involved is staff activity at the universitywhich therefore accounts for most of the social footprintthe activity that supports the transport services demanded by the UPV/EHU also has a very significant impact on the social footprint. In fact, the results show that the social risks related to the academic activity of the UPV/EHU are spread worldwide through other economic sectors that indirectly support it, through the supply of energy, materials, waste treatment, and transport services. The effort to achieve a more sustainable academic activity in HEIs could benefit from the application of tools and methods, like SO-LCA, capable of analysing the geographical distribution and the most significant sources of social risks in these upstream chains (Di Noi et al. 2020). In practical terms, studies such as ours should serve to establish specific measures to reduce or even mitigate the social impacts generated. Thus, one line of work in our research is the assessment of different future scenarios (e.g. extending computers lifetime, transferring journeys from cars to bus or coach) that will allow us to devise concrete action measures associated with those scenarios. This task will be carried out by means of the Multicriteria Decision Analysis (MCDA) methodology (Figueira et al. 2016; Doumpos et al. 2019) and with the participation of the stakeholders involved in the management of the UPV/ EHU.

With respect to the geographical analysis carried out in our case study, unlike environmental impacts (Bueno et al. 2021), social impacts are mainly located in the ACBC, both in relation to the direct impact of academic activity and to the socioeconomic activities that support it. But the geographical analysis reveals that the UPV/EHU presents a social footprint with impacts that also occur far away from the geographical area of influence of the activity analysed, in this case the ACBC; this is true, for example, of child labour or illiteracy in geographical areas that indirectly support the academic activity of the UPV/EHU. From this, it could be inferred that the activity or product/service analysed may generate a social debt with third countries. Similar to ecological debt, which countries of the global North incur with those of the global South as a result of the ecological impacts generated in the latter countries over decades (Srinivasan et al. 2008), social debt would reflect the accumulated burden in social terms that the countries generating these impacts incur with the countries that suffer them. Thus, the generating societies would be indebted to those suffering the social impacts. Social debt has barely 
been addressed in the literature from this perspective, with a few exceptions (Pengue 2005). One of the ways to move forward in this regard may be to use the social footprint for estimating such a debt in terms of compensation and even reparation of the social debt (see, e.g. Torras 2003). The adoption of measures that contribute to reducing the social debt of the UPV/EHU would be desirable. In any case, analyses of this kind in HEIs are necessary to reduce their social footprint and improve their performance in terms of social equity and equality. SO-LCA analyses are also complementary to those focusing on the environmental impacts of HEIs (Lopes Silva et al. 2015; Sinha et al. 2010), all of which should ultimately result in the valuable contribution that HEIs make to knowledge, progress and human values. Nonetheless, further analysis would be needed to define the geographical location of social impacts more precisely, an issue that poses one of the main challenges in the SO-LCA framework (Martínez-Blanco et al. 2015b).

Regarding SDGs, our analysis reveals that social impact indicators presenting a higher social risk level are related to SDG1 (No Poverty), SDG4 (Quality Education), SDG5 (Gender Equality), SDG8 (Decent Work and Economic Growth), and SDG10 (Reduced Inequality). Thus, if the UPV/EHU is to align itself with the 2030 Agenda (Sáez de Cámara et al. 2021; UPV/EHU 2019a), it should pay special attention to the above-mentioned SDGs. The implementation of a series of measures to improve the performance of the UPV/EHU in the aforementioned SDGs could compensate for the social debt generated by the social footprint. However, this must be complemented with an awareness of the social reality upon which the academic activity relies. Some of these social impacts, often geographically distant and sometimes harmful, are not directly generated by the institution but, nevertheless, truly demand attention and responsibility.

\section{Conclusions}

In this study, data collection and analysis with the PSILCAbased Soca add-on of the social impacts derived from the academic activity of the UPV/EHU have been presented in detail.

Our analysis has contributed to methodological advancements in SO-LCA. For the calculation of final social direct impacts and equivalent risk levels, we have carried out an alternative strategy consisting of applying the ratio between the central values of each value range considered by the PSILCA database for each level of risk. Although approximate, in our view, this method is more accurate as it avoids certain arbitrary risk level equivalences as applied by the openLCA software with the Soca add-on.
The results for the social footprint of the academic activity of the UPV/EHU reveal information for four relevant stakeholder groups: Workers, Local community, Society, and Value Chain Actors. While for some impact categories the risk level of the social footprint remains the same as in the area taken as a reference (the Autonomous Community of the Basque Country, Spain), there are some social impact categories where the social footprint presents a higher risk level, implying that there are activities throughout the life cycle of the academic activity that occur outside the UPV/ EHU and are found in a socio-economic context where the social impact diverges from that within the surrounding socio-economic context in which the UPV/EHU is located.

Results show that labour activity at the UPV/EHU is the most significant sub-process within the social footprint with respect to most of the indicators that were analysed, followed by transportation-related sub-processes. A transition to more sustainable transport modes with less harmful social footprints could be one possible way to decrease risks in this regard. This transition may include options such as: increasing the occupancy rate of private cars, moving transport from private cars to public transport, reducing campus attendance by implementing a 4-day week, and promoting the change of the usual residence to places closer to the campus, in order to avoid commuting longer distances; their specific characteristics and potential to reduce environmental impacts are detailed in Zuazo et al. (Zuazo I, Torre-Pascual $\mathrm{E}$, Bueno $\mathrm{G}$ et al. The environmental footprint of the mobility needs of the University of the Basque Country UPV/ EHU, Unpublished) and Bueno et al. (Bueno G, de Blas $\mathrm{M}$, Pérez-Iribarren E et al. Dataset on the environmental and social footprint of the University of the Basque Country UPV/EHU, Unpublished work).

Although this work is focused on a specific case study, we truly believe that both the proposed methodology and the set of conclusions could be applied to other HEIs and organisations. Using a methodology based on SO-LCA has proven to be adequate for detecting critical points and specific drawbacks of an organisation's social footprint. In addition, the results obtained for the academic activity of the UPV/EHU can serve as a basis for further research.

Overall, SO-LCA is still a rather young concept and methods and data availability are constantly developing. One main issue would be to more accurately locate the geographical distribution of social impacts by countries. In our analysis, a further challenge would be to try to determine the geographical location of impacts more precisely. In addition, further development of the theoretical corpus around the concept of social debt also poses a challenge for future research. The advances on the SO-LCA arena can contribute to this insofar as it is linked to developing the assessment of social footprints. Moreover, some limitations are identified with regard to social performance tracking. Indeed, 
SO-LCA results may vary whenever the suppliers' network is changed, but as SO-LCA is an emerging field, performance tracking is difficult (Benoit et al. 2020). Finally, the methodology applied in this study has limitations in measuring how much an organisation contributes to the fulfilment of the SDGs, but it is already useful to give an indication of which SDGs it can influence the most, and may be used as an internal social management tool for organisations that facilitates decision-making within the SDG framework.

Acknowledgements To the Sustainability Directorate and the Educational Advisory Service, both belonging to the Vice-Chancellor's Office for Innovation, Social Commitment and Social Action of the University of the Basque Country UPV/EHU, in the context of the Campus Bizia Lab programme (2017/18, 18/19 and 19/20 calls) for the financing of the EHU-Aztarna project.

Funding Open Access funding provided thanks to the CRUE-CSIC agreement with Springer Nature. This research has been supported by "Ekopol: Iraunkortasunerako Bideak" research group, recognised by the Basque Government (IT-1365-19) and the University of the Basque Country UPV/EHU (GIC-18/22).

\section{Declarations}

Competing interests The authors declare no competing interests.

Open Access This article is licensed under a Creative Commons Attribution 4.0 International License, which permits use, sharing, adaptation, distribution and reproduction in any medium or format, as long as you give appropriate credit to the original author(s) and the source, provide a link to the Creative Commons licence, and indicate if changes were made. The images or other third party material in this article are included in the article's Creative Commons licence, unless indicated otherwise in a credit line to the material. If material is not included in the article's Creative Commons licence and your intended use is not permitted by statutory regulation or exceeds the permitted use, you will need to obtain permission directly from the copyright holder. To view a copy of this licence, visit http://creativecommons.org/licenses/by/4.0/.

\section{References}

Benoît C, Traverso M, Valdivia S et al (2013) The methodological sheets for sub-categories in social life cycle assessment (S-LCA)

Benoît C, Mazijn B (2009) UNEP/SETAC life cycle initiative-guidelines for social life cycle assessment of products

Benoît C, Traverso M, Neugebauer S et al (2020) Guidelines for social life cycle assessment of products and organisations 2020

Bueno G, de Blas M, Pérez-Iribarren E et al (2021) The environmental and social footprint of the University of the Basque Country (UPV/EHU). J Clean Prod 315(30):128109. https://doi.org/10. 1016/j.jclepro.2021.128019

Ciroth A (2007) ICT for environment in life cycle applications openLCA - a new open source software for life cycle assessment. Int J Life Cycle Assess 12:209-210. https://doi.org/10.1065/lca2007. 06.337

Ciroth A, Eisfeldt F (2016) PSILCA-A product social impact life cycle assessment database version 1.0

Ciroth A, Franze J (2011) LCA of an ecolabeled notebook-consideration of social and environmental impacts along the entire life cycle. 409
D’Eusanio M, Lehmann A, Finkbeiner M, Petti L (2020) Social organizational life cycle assessment: an approach for identification of relevant subcategories for wine production in Italy. Int J Life Cycle Assess 25:1119-1132. https://doi.org/10.1007/s11367-020-01746-4

Di Noi C, Ciroth A, Mancini L et al (2020) Can S-LCA methodology support responsible sourcing of raw materials in EU policy context? Int J Life Cycle Assess 25:332-349. https://doi.org/10. 1007/s11367-019-01678-8

Doumpos M, Figueira JR, Greco S, Zopounidis C (eds) (2019) New perspectives in multiple criteria decision making. Springer International Publishing, Cham

Eisfeldt F (2017) Soca v.1 add-on—adding social impact information to ecoinvent

Eustat (2020) Basque Statistical Office - Euskal Estatistika Erakundea - Instituto Vasco de Estadística. https://en.eustat.eus/indice.html. Accessed 25 Sep 2020

Figueira J, Greco S, Ehrogott M (2016) Multiple criteria decision analysis. Springer, New York, New York, NY

Forin S, Martínez-Blanco J, Finkbeiner M (2019) Facts and figures from road testing the guidance on organizational life cycle assessment. Int J Life Cycle Assess 24:866-880. https://doi. org/10.1007/s11367-018-1533-x

Gompf K, Traverso M, Hetterich J (2020) Towards social life cycle assessment of mobility services: systematic literature review and the way forward. Int J Life Cycle Assess 25:1883-1909. https://doi.org/10.1007/s11367-020-01788-8

Hauschild MZ, Rosenbaum RK, Olsen SI (eds) (2018) Life cycle assessment. Springer International Publishing, Cham

Herrera Almanza AM, Corona B (2020) Using social life cycle assessment to analyze the contribution of products to the Sustainable Development Goals: a case study in the textile sector. Int J Life Cycle Assess 25:https://doi.org/10.1007/ s11367-020-01789-7

Jarosch L, Zeug W, Bezama A et al (2020) A regional socio-economic life cycle assessment of a bioeconomy value chain. Sustainability 12:1259. https://doi.org/10.3390/su12031259

Lo-Iacono-Ferreira VG, Torregrosa-López JI, Capuz-Rizo SF (2017) Organizational life cycle assessment: suitability for higher education institutions with environmental management systems. Int J Life Cycle Assess 22:1928-1943. https://doi.org/10.1007/ s11367-017-1289-8

Lopes Silva DA, De Oliveira JA, Saavedra YMB et al (2015) Combined MFA and LCA approach to evaluate the metabolism of service polygons: a case study on a university campus. Resour Conserv Recycl 94:157-168. https://doi.org/10.1016/j.resconrec.2014.11. 001

Lozano R, Ceulemans K, Alonso-Almeida M et al (2015) A review of commitment and implementation of sustainable development in higher education: results from a worldwide survey. J Clean Prod 108:1-18. https://doi.org/10.1016/J.JCLEPRO.2014.09.048

Martínez-Blanco J, Finkbeiner M (2018) Organisational LCA. In: Life cycle assessment. springer international publishing, Cham, pp 481-498

Martínez-Blanco J, Inaba A, Quiros A et al (2015a) Organizational LCA: the new member of the LCA family-introducing the UNEP/SETAC Life Cycle Initiative guidance document. Int J Life Cycle Assess 20:1045-1047. https://doi.org/10.1007/ s11367-015-0912-9

Martínez-Blanco J, Lehmann A, Chang YJ, Finkbeiner M (2015b) Social organizational LCA (SOLCA) - a new approach for implementing social LCA. Int J Life Cycle Assess 20:1586-1599. https://doi.org/10.1007/s11367-015-0960-1

Martínez-Blanco J, Inaba A, Finkbeiner M (2015c) Scoping organizational LCA - challenges and solutions. Int J Life Cycle Assess 20:829-841. https://doi.org/10.1007/s11367-015-0883-x 
Moltesen A, Bonou A, Wangel A, Bozhilova-Kisheva KP (2018) Social life cycle assessment: an introduction. Life Cycle Assessment. Springer International Publishing, Cham, pp 401-422

Numbeo (2020) Pollution in Bilbao - Numbeo. https://www.numbeo. com/pollution/in/Bilbao. Accessed 25 Sep 2020

Pelletier N, Allacker K, Manfredi S et al (2012) Organisation Environmental Footprint (OEF) Guide

Pelletier N, Allacker K, Pant R, Manfredi S (2014) The European Commission Organisation Environmental Footprint method: comparison with other methods, and rationales for key requirements. Int J Life Cycle Assess 19:387-404. https://doi.org/10. 1007/s11367-013-0609-x

Pengue WA (2005) Transgenic crops in Argentina: the ecological and social debt. Bull Sci Technol Soc 25:314-322

Petti L, Serreli M, Di Cesare S (2018) Systematic literature review in social life cycle assessment. Int J Life Cycle Assess 23:422-431

Sáez de Cámara E, Fernández I, Castillo-Eguskitza N (2021) A holistic approach to integrate and evaluate sustainable development in higher education. The case study of the University of the Basque Country. Sustainability 13:392. https://doi.org/10.3390/ su13010392

Sinha P, Schew WA, Sawant A et al (2010) Greenhouse gas emissions from U.S. institutions of higher education. J Air Waste Manag Assoc 60:568-573. https://doi.org/10.3155/1047-3289.60.5.568

Srinivasan UT, Carey SP, Hallstein E et al (2008) The Debt of Nations and the Distribution of Ecological Impacts from Human Activities 105:1768-1773
Torras M (2003) An ecological footprint approach to external debt relief. World Dev 31:2161-2171. https://doi.org/10.1016/j. worlddev.2003.09.001

UNEP/SETAC (2015) Guidance on organizational life cycle assessment. Life-Cycle Initiative. Paris, France

UPV/EHU (2019a) EHUagenda 2030 for Sustainable Development

UPV/EHU (2019b) Panel de Indicadores de Desarrollo Sostenible de la UPV/EHU

UPV/EHU (2020a) Localization - UPV/EHU. https://www.ehu.eus/es/ ikastegien-kokapena. Accessed 8 May 2020

UPV/EHU (2020b) Presupuestos - Portal de Transparencia - UPV/EHU. https://www.ehu.eus/es/web/gardentasun-ataria/aurrekontuak. Accessed 14 May 2020

UPV/EHU (2020c) UPV/EHU in figures I UPV/EHU zenbakitan. http:// www.ehu.eus/zenbakitan/en/node/1.html. Accessed 8 May 2020

URA (2020) Basque Office for Water - Uraren Euskal Agentzia Agencia Vasca del Agua. https://www.uragentzia.euskadi.eus/ u81-0002/es/. Accessed 25 Sep 2020

Werker J, Wulf C, Zapp P et al (2019) Social LCA for rare earth NdFeB permanent magnets. Sustain Prod Consum 19:257-269. https:// doi.org/10.1016/J.SPC.2019.07.006

Publisher's Note Springer Nature remains neutral with regard to jurisdictional claims in published maps and institutional affiliations. 